Published in final edited form as:

Heart Rhythm. 2015 January ; 12(1): e5-e29. doi:10.1016/j.hrthm.2014.11.011.

\title{
Progress toward the prevention and treatment of atrial fibrillation: A summary of the Heart Rhythm Society Research Forum on the Treatment and Prevention of Atrial Fibrillation, Washington, DC, December 9-10, 2013
}

\section{David R. Van Wagoner, PhD, FHRS ${ }^{1,{ }^{*}, \text {, }}$, Jonathan P. Piccini, MD, MHS, FHRS ${ }^{2,}$, Christine} M. Albert, MD, MPH $^{3}$, Mark E. Anderson, MD, PhD, FHRS ${ }^{4}$, Emelia J. Benjamin, MD, ScM ${ }^{5}$, Bianca Brundel, $\mathrm{PhD}^{6}$, Robert M. Califf, MD ${ }^{7}$, Hugh Calkins, MD, $\mathrm{FHRS}^{8}$, Peng-Sheng Chen, MD, FHRS ${ }^{9}$, Nipavan Chiamvimonvat, MD ${ }^{10}$, Dawood Darbar, MD, FHRS ${ }^{11}$, Lee L. Eckhardt, MD, FHRS ${ }^{12}$, Patrick T. Ellinor, MD, PhD ${ }^{13}$, Derek V. Exner, MD, MPH, FHRS ${ }^{14}$, Richard I. Fogel, MD, FHRS, FACC ${ }^{15}$, Anne M. Gillis, MD, FHRS ${ }^{16}$, Jeff Healey, MD, MSc, FHRS ${ }^{17}$, Stefan H. Hohnloser, MD, FHRS ${ }^{18}$, Hooman Kamel, MD ${ }^{19}$, David A. Lathrop, PhD $^{20}$, Gregory Y.H. Lip, MD ${ }^{21}$, Reena Mehra, MD, MS ${ }^{22}$, Sanjiv M. Narayan, MD, PhD, FHRS ${ }^{23}$, Jeffrey Olgin, MD, FHRS ${ }^{24}$, Douglas Packer, MD, FHRS ${ }^{25}$, Nicholas S. Peters, MD, FHRS ${ }^{26}$, Dan M. Roden, MD, FHRS ${ }^{27}$, Heather M. Ross, DNP, ANP-BC, FHRS ${ }^{28}$, Robert Sheldon, MD, PhD, FHRS, FRCPC ${ }^{29}$, and Xander H.T. Wehrens, MD, PhD, FHRS ${ }^{30}$

${ }^{1}$ Cleveland Clinic Lerner College of Medicine of Case Western Research University

2Duke University Medical Center, Duke Clinical Research Institute

${ }^{3}$ Brigham and Women's Hospital and Harvard Medical School

${ }^{4}$ Johns Hopkins University School of Medicine

${ }^{5}$ Boston University Schools of Medicine \& Public Health

6University Medical Center Groningen

${ }^{7}$ Duke Translational Medicine Institute

8 Johns Hopkins University School of Medicine

${ }^{9}$ Krannert Institute of Cardiology, Indiana University School of Medicine

${ }^{10}$ University of California, Davis and the Department of Veterans Affairs, Northern California Health Care System

${ }^{11}$ Vanderbilt University Medical Center

${ }^{12}$ University of Wisconsin-Madison

\footnotetext{
(C) 2015 Heart Rhythm Society. Published by Elsevier Inc. All rights reserved.

*Address reprint requests and correspondence: Forum Chair and Communicating Author: Dr. David R. Van Wagoner, Department of Molecular Cardiology, NE-61, 9500 Euclid Avenue, Cleveland, OH 44195. vanwagd@ @ccf.org.

Il Co-first authors; equal contributions to manuscript preparation.

Developed in collaboration with and endorsed by the European Heart Rhythm Association (EHRA) and the Canadian Heart Rhythm Society (CHRS).

Appendix A. Supplementary Materials: See Table A1.
} 
${ }^{13}$ Massachusetts General Hospital, Broad Institute, and Harvard Medical School

${ }^{14}$ Libin Cardiovascular Institute of Alberta, University of Calgary

${ }^{15}$ St.Vincent Medical Group

${ }^{16}$ Libin Cardiovascular Institute of Alberta, University of Calgary

${ }^{17}$ Hamilton Health Sciences, McMaster University

${ }^{18} \mathrm{~J} . W$. Goethe University, Frankfurt, Germany

${ }^{19}$ Weill Cornell Medical College

${ }^{20}$ National Heart, Lung, and Blood Institute, National Institutes of Health

${ }^{21}$ University of Birmingham, United Kingdom, and Aalborg University, Denmark

${ }^{22}$ Cleveland Clinic Lerner College of Medicine of Case Western Research University

${ }^{23}$ Stanford University

${ }^{24}$ University of California San Francisco

${ }^{25}$ Mayo Clinic

${ }^{26}$ Imperial College \& Imperial NHS Trust, London

${ }^{27}$ Vanderbilt University School of Medicine

${ }^{28}$ Arizona State University

${ }^{29}$ Libin Cardiovascular Institute of Alberta, University of Calgary

${ }^{30}$ Baylor College of Medicine

\section{Introduction}

The Heart Rhythm Society convened a research symposium on December 9-10, 2013, in Washington, DC, that focused on the prevention of atrial fibrillation (AF) as well as AFrelated stroke and morbidity. Attendees sought to summarize advances in understanding AF since a 2008 National Institutes of Health (NIH) conference on this topic ${ }^{1}$ and to identify continued knowledge gaps and current research priorities. The research symposium also sought to identify key deficiencies and opportunities in research infrastructure, operations, and methodologies. The committee sought to identify both basic research targets and how clinical AF research could be improved in the current health care environment. This whitepaper summarizes our deliberations in an effort to accelerate progress toward preventing $\mathrm{AF}$ and its consequences. Although largely focused on primary prevention of AF, the paper also addresses some aspects of secondary prevention of recurrent AF due to the continuum of risk factors that contribute to arrhythmogenesis, permissive left atrial (LA) substrates, and the emergence of AF. 


\section{Scope of the problem}

More than 33 million individuals worldwide have AF, and there are approximately 5 million new cases each year. ${ }^{2} \mathrm{AF}$ incidence and prevalence increase with age; the prevalence of $\mathrm{AF}$ increases 3-fold between the 6th and 8th decade of life. The increasing frequency of AF is particularly notable in industrialized nations where the increment in AF is more than 2-fold greater than in developing nations. ${ }^{2}$ Based on estimates from the Framingham Study, the lifetime risk of developing AF has been estimated at 1 in $4 .{ }^{3}$ Accordingly, treatment of AF has been targeted as a top priority for comparative effectiveness research by the Institute of Medicine. ${ }^{4}$

AF leads to a 5-fold increased risk of stroke, a 2-fold risk of dementia, as well as increased risk of myocardial infarction, heart failure (HF), and death. ${ }^{5}$ Over the past 2 decades, hospital admissions for AF have increased by two-thirds. Direct expenditures related to AF cost Medicare at least $\$ 6$ billion annually. ${ }^{5}$ In addition to higher morbidity and mortality, AF-related strokes are associated with $20 \%$ greater health care costs relative to non-AF strokes. ${ }^{6}$ Currently approved AF therapies are only partially effective and are associated with substantial morbidity and mortality. Whereas many studies have focused on the treatment of AF, relatively few have been directed at prevention of AF. In contrast to coronary heart disease and stroke, preventive strategies and therapies for AF remain unproven. ${ }^{1}$

Analysis of clinical practice guidelines reveals a gap between the need for evidence and its availability. ${ }^{7}$ Patients seek evidence-based guidance related to diet, exercise, and lifestyle for risk factor modification and $\mathrm{AF}$ prevention, but systematic studies in these areas are currently quite limited. More research is required to support evidence-based recommendations as part of a comprehensive approach to prevention and treatment of $\mathrm{AF}$. Developing an evidence base from which we can adequately predict and prevent AF is an important public health goal.

Most trials are underpowered to answer clinically meaningful questions, and many critical trials funded by industry and the NIH are not published. ${ }^{8,9}$ These findings suggest that the clinical research enterprise lacks effective prioritization. There is currently no (1) consensusderived list of top priorities for research in AF nor (2) a systematic portfolio analysis focused on benefit to patients or providers. This manuscript seeks to begin to address these gaps.

\section{Recent progress with respect to fundamental AF mechanisms, key knowledge gaps, and therapeutic opportunities Relation of atrial ectopy to development of AF}

Frequent atrial ectopy (premature atrial contractions [PACs]) during 24-hour Holter recordings has been identified as a strong predictor of AF development, with discriminatory power similar to the Framingham risk score over 5 to 10 years of follow-up and even better at 15 years. ${ }^{10}$ Atrial ectopy has significant prognostic potential that may help to identify patients at greatest risk for $\mathrm{AF}$ and for whom early treatment may enable primary prevention 
of AF. PAC frequency has been positively associated with age, height, and brain natriuretic peptide (BNP) levels; PAC frequency has been inversely related to HDL levels and physical activity. ${ }^{11}$ Studies testing the causal link(s) between PAC burden and incident AF are needed. Studies testing the hypothesis that early treatment in these patients is beneficial are also warranted, but the current lack of therapies that are both highly effective and safe remains an obstacle. Safety is a critical consideration in preventive medicine. ${ }^{12}$

Ectopy is a common trigger for AF initiation; frequent ectopy has been associated with both incident ${ }^{10}$ and postoperative AF. ${ }^{13}$ Ectopy arises from 3 general mechanisms: (1) atrial automaticity, (2) early afterdepolarizations (EADs), and (3) delayed afterdepolarizations (DADs). EADs and DADs are triggered activities that occur during and after action potential repolarization, respectively. Triggered activity can be caused by any condition that enhances net inward current (influx of $\mathrm{Na}^{+}$or $\mathrm{Ca}^{2+}$ ions, relative to efflux of $\mathrm{K}^{+}$ions).

AF represents an interaction between focal or triggered activity that initiates AF episodes and development of a "vulnerable substrate" critical for AF persistence. ${ }^{14}$ Reentry can result from altered electrical properties (a "functional substrate") and may contribute to persistent AF. Functional reentry mechanisms include abbreviation of atrial refractoriness and/or slowed conduction allowing the impulse to reenter the circuit. Focal ectopy arising from the muscular sleeves encircling the pulmonary veins $(\mathrm{PVs})^{15}$ often provokes paroxysmal atrial fibrillation (pAF) episodes, whereas functional and fixed substrates (ie, atrial scar) play increasing roles as AF becomes persistent and permanent, respectively. ${ }^{14}$ Persistent AF promotes both electrical remodeling (changes in ion channel expression or activity) and structural remodeling (interstitial fibrosis, myocyte hypertrophy, apoptosis, etc) of the atria.

\section{Atrial sodium and calcium handling}

Cardiac conduction is primarily attributable to the activity of voltage-gated $\mathrm{Na}^{+}$channels (Nav1.5). Sodium current $\left(\mathrm{I}_{\mathrm{Na}}\right)$ normally activates and then inactivates fully within a few milliseconds. During HF and in some cases of AF, delayed inactivation results in a persistent or "late" component of $\mathrm{I}_{\mathrm{Na}}$. Late $\mathrm{I}_{\mathrm{Na}}$ hinders $\mathrm{Ca}^{2+}$ extrusion by the $\mathrm{Na}^{+} / \mathrm{Ca}^{2+}$ exchanger, altering intracellular $\mathrm{Ca}^{2+}$ regulation.

Many recent studies have revealed a critical role for calcium $\left(\mathrm{Ca}^{2+}\right)$ handling abnormalities in the etiology of AF. Atrial myocytes isolated from cardiac surgery patients have shown that $\mathrm{AF}$ is associated with enhanced spontaneous $\mathrm{Ca}^{2+}$ release from intracellular stores in the sarcoplasmic reticulum (SR). ${ }^{16}$ In atrial myocytes from persistent AF patients, enhanced activity of $\mathrm{Ca}^{2+} /$ calmodulin-dependent kinase II (CaMKII) has a central role in the dysregulation of intracellular $\mathrm{Ca}^{2+}$ handling. ${ }^{16}$ Although phosphorylation and activation of CaMKII are the normal responses to elevated cytosolic $\mathrm{Ca}^{2+}$ levels, pathologic CaMKII activation can result from several posttranslational modifications, including methionine oxidation. ${ }^{17}$ In persistent AF, the type 2 ryanodine receptor (RyR2), the primary intracellular $\mathrm{Ca}^{2+}$ release channel, is a major target of CaMKII. ${ }^{16}$ Increased RyR2 phosphorylation by CaMKII promotes diastolic $\mathrm{SR} \mathrm{Ca}^{2+}$ leak that can cause DADs. In persistent AF patients, CaMKII inhibitors normalized $\mathrm{Ca}^{2+}$ handling. ${ }^{16}$ Increased Protein kinase A (PKA) phosphorylation and reduced protein phosphatase activity may also 
contribute to RyR2 dysfunction in AF. ${ }^{16}$ CaMKII-mediated calcium dysregulation in AF has been reviewed in a recent publication. ${ }^{17}$

Increased SR $\mathrm{Ca}^{2+}$ leak and spontaneous $\mathrm{SR} \mathrm{Ca}^{2+}$ release events have also been found in studies of atrial myocytes from patients with $\mathrm{pAF}$, but these events seem to be CaMKII independent because CaMKII autophosphorylation and RyR2 phosphorylation levels were unaltered..$^{18}$ Because the tissue was harvested while atria were in sinus rhythm, it is unknown if CaMKII activation occurs during or immediately prior to pAF. Lower expression of junctophilin-2 (JPH2) relative to RyR2 has been proposed to promote RyR2mediated SR $\mathrm{Ca}^{2+}$ leak in pAF patients, as JPH2-deficient mice are susceptible to AF. ${ }^{19}$ To prevent the early atrial ectopy that initiates $\mathrm{pAF}$, additional research is still needed into the mechanisms promoting atrial arrhythmogenesis, both in patient samples and in relevant animal models. As previously recognized, creation of large animal models that develop spontaneous atrial ectopy and pAF would facilitate evaluation of the mechanisms and sources of atrial ectopy that underlie the early stages of atrial arrhythmogenesis. ${ }^{1,16}$

\section{Key knowledge gaps}

1. What calcium handling (and other) mechanisms underlie ectopic PV activity in pAF patients?

2. Why does ectopy initiating from the PVs or other structures (vein of Marshall, coronary sinus, superior vena cava, etc) predominantly result in AF only in older individuals?

3. Are the mechanisms that underlie PV ectopy the same as those originating from other atrial regions?

4. Can targeted treatment of patients with frequent atrial ectopy safely and effectively prevent development of AF?

\section{Pharmacotherapy for AF prevention/treatment}

Drugs currently approved for AF management typically either block sodium channels to reduce excitability or block potassium channels to prolong repolarization. These drugs have limited efficacy and potentially serious side effects, most notably ventricular proarrhythmia. Some less specific drugs (amiodarone, dronedarone, ranolazine, etc) affect multiple channels and pathways, and are less proarrhythmic than agents that act on a single ion channel. An alternative strategy to ion channel blockade is to identify potential "upstream" targets. A recent comprehensive review of AF mechanisms and candidate drug targets details these possibilities. ${ }^{20}$ Here we briefly consider several newer AF drug targets in relation to the phases of AF development.

Atrial sodium and calcium handling-Ranolazine is currently approved by the US Food and Drug Administration (FDA) for treatment of chronic angina. It somewhat selectively suppresses late $\mathrm{I}_{\mathrm{Na}}$ and has been shown to protect against postoperative $\mathrm{AF}$ in coronary artery bypass patients, ${ }^{21}$ a setting in which $\mathrm{AF}$ is promoted by elevated catecholamines and oxidant stress. In addition to CaMKII effects on RyR2, CaMKII hyperactivation also augments late $\mathrm{I}_{\mathrm{Na}}{ }^{22}$ Ranolazine-mediated block of late $\mathrm{I}_{\mathrm{Na}}$ may be 
antiarrhythmic in part by attenuating CaMKII activation, as a consequence of improved export of intracellular $\mathrm{Ca}^{2+}$ by the $\mathrm{Na}^{+} / \mathrm{Ca}^{2+}$ exchanger. Ranolazine may also attenuate mitochondrial oxidant production. ${ }^{23}$

CaMKII, pathologically activated by oxidative stress, ${ }^{24}$ can phosphorylate many voltagegated ion channels in the heart, can stimulate inflammatory signaling by bolstering nuclear factor for $\kappa \mathrm{B}(\mathrm{NF}-\kappa \mathrm{B}),{ }^{25}$ and can promote tissue remodeling and fibrosis by promoting myocyte cell death and expression of matrix metalloproteinase-9 (MMP9). ${ }^{26} \mathrm{CaMKII}$ inhibition and late $\mathrm{I}_{\mathrm{Na}}$ suppression strategies both are appealing because they are antiarrhythmic for ventricular as well as atrial arrhythmias, reducing concern about proarrhythmia. No CaMKII inhibitory agents are clinically available yet, but several are in development for cardiovascular indications including AF and likely will be available in 3-5 years for proof-of-concept AF prevention studies.

Atrial oxidant stress/redox status-Because oxidant stress is upstream of late $\mathrm{I}_{\mathrm{Na}}$, CaMKII activation, and fibroblast and matrix metalloproteinase (MMP) activation, efforts to target oxidant generating sources in the atria seem logical. There is evidence for increased NADPH oxidase-2 (NOX2) activity in AF. ${ }^{27} \mathrm{NOX} 2$ can be directly activated by myocyte stretch, and NOX2 activity modulates intracellular $\mathrm{Ca}^{2+}$ release. ${ }^{28}$ Other oxidant generating systems (NOX4, xanthine oxidase, myeloperoxidase) may also be important, with different oxidant generating systems likely relevant for patients with distinct subtypes of AF.

Flecainide ${ }^{29}$ and carvedilol ${ }^{30}$ have antiarrhythmic activities that result in part from redox modulation of RyR2; further mechanistic study of these drugs in secondary prevention of AF may be warranted. JTV-519, another RyR2 modulating drug, reduced $\mathrm{Ca}^{2+}$ leak and showed efficacy against AF but was withdrawn from clinical development due to ventricular proarrhythmia. JTV-519 derivatives are in clinical trials for HF and may prove useful in AF. ${ }^{31}$

Conduction velocity/heterogeneity-AF maintenance is facilitated by electrical/tissue remodeling that supports functional and structural reentry. As electrical reentry is favored by conditions that slow conduction or accelerate action potential repolarization, antiarrhythmic strategies may seek to repair slowed conduction and/or delay action potential repolarization. Experimental atrial gene therapy with connexin 40 or connexin 43 has been demonstrated to preserve conduction velocity and prevent AF initiation. ${ }^{32}$ Drugs in development target defective conduction velocity either by enhancing gap junction conductance (rotigaptide and others) or by attenuating atrial fibrosis (pirfenidone and others). ${ }^{20}$

Atrial-specific ion channels-Several ion channels are expressed more abundantly in atrial than ventricular myocardium. Therefore, these atrial-"specific" channels represent possible drug targets with little risk of ventricular proarrhythmia. ${ }^{33}$ Intracellular $\mathrm{Ca}^{2+}$ levels preferentially modulate atrial (vs ventricular) repolarization due to chamber specific differences in expression of $\mathrm{Ca}^{2+}$-activated potassium channel subunits (especially KCNN2 and KCNN3). ${ }^{34}$ Genome-wide studies have associated $\mathrm{KCNN} 3$ variants with $\mathrm{AF}$ risk. ${ }^{35}$ Expression of these channels is altered in experimental AF models, ${ }^{36,37}$ and agents that selectively suppress KCNN channel activity have been shown to exhibit antiarrhythmic 
activity. ${ }^{37}$ These channels may also have important roles in other cell types (neurons, fibroblasts, vascular smooth muscle) that could affect AF risk.

\section{Atrial structural remodeling/fibrosis}

The atria are hemodynamically responsive endocrine organs. Under increased pressure, the atria release peptide hormones (atrial natriuretic peptide [ANP], BNP, endothelin-1 [ET-1], angiotensin-II [A-II], etc) that facilitate blood pressure (BP) and blood volume regulation. ${ }^{38}$ These stretch-modulated hormones have autocrine, paracrine, and circulating activities, affecting the heart, lungs, blood vessels, and kidneys. The atria respond to acutely increased pressure by releasing natriuretic peptides (NPs) from myocytes that promote renal sodium excretion to lower systemic BP and volume. NPs also modulate systemic and coronary vascular tone and the electrical activity of cardiac myocytes via NP receptor-mediated activation of guanylate cyclase (GC). GC produces cGMP, which counteracts the effects of cAMP formed in response to sympathetic nerve activity (via beta-adrenergic receptor activation).

Changes in atrial structure, contractility, and electrical activity resulting from AF or underlying hemodynamic stress are due in part to the local impact of A-II, ET-1, ANP, and BNP release on atrial myocytes and fibroblasts. In the face of persistently elevated diastolic pressure (from hypertension, valvular dysfunction, HF, lung disease, and/or AF), the atria hypertrophy and develop interstitial fibrosis as a result of activation of the reninangiotensin-aldosterone system (RAAS), ET-1, and transforming growth factor- $\beta$ (TGF- $\beta$ ) signaling pathways. ${ }^{39}$ Atrial fibrosis is also promoted by the activity of the transient receptor potential cation channel, subfamily M, member 7 (TRPM7), TRPC3, and by loss of the antifibrotic micro RNA-29 (miR-29). ${ }^{16}$ Atrial interstitial fibrosis promotes slowed and heterogeneous conduction. ${ }^{40}$ Fibrosis represents a response to injury, in the atria as well as in the lung, kidney, liver, and other organs.

Candidate antifibrotic therapies with the potential to slow or prevent the transition from paroxysmal to persistent AF include small molecule TGF- $\beta$ antagonists, selective TRPM7 or TRPC 3 antagonists, and miR-29 mimetics. ${ }^{16}$ In experimental hypertension and HF studies, pretreatment with agents that suppress TGF- $\beta$ signaling or the RAAS (pirfenidone, spironolactone, omega-3 fatty acids, angiotensin-converting enzyme inhibitors/angiotensin receptor blockers [ACEi/ARBs]) have prevented or attenuated development of atrial fibrosis. Although effective when given before persistent hemodynamic stress, ${ }^{41}$ preclinical and clinical trial evidence so far has failed to demonstrate an antiarrhythmic benefit of these drugs in the treatment of AF in the presence of established HF.

Proteostasis and the microtubule network in AF-Aging is a powerful but nonmodifiable risk factor for AF. The proteostasis network is involved in the degradation of "old" proteins, the synthesis of new proteins within the endoplasmic reticulum (ER), and folding and trafficking of native proteins. Age-related conditions associated with abnormal proteostasis include Alzheimer, Parkinson, and Huntington diseases. ${ }^{42}$ Like these conditions, AF is also a strongly age-related disease associated with defective proteostatic 
control. ${ }^{43}$ Figure 1 provides an overview of the primary proteostasis pathways, related signaling pathways, and significant modifiers of proteostasis. ${ }^{44}$

In several experimental AF models, normalization of proteostasis by overexpressing heat shock proteins (HSPs) attenuates structural remodeling and AF progression. ${ }^{45}$ HSPB1 binds to myofibrils and protects them from degradation in experimental systems and in human AF. ${ }^{45}$ HSPB1 also prevents structural remodeling by attenuating the conversion of G-actin to F-actin stress fibers and consequently protects against contractile dysfunction. Although the HSP response is transiently activated in patients with short episodes of AF, it becomes exhausted when AF persists. Atrial myocytes then lose their defense against structural changes, leading to AF progression. ${ }^{45}$ Atrial HSP expression may be a novel target for AF treatment. ${ }^{46}$ Geranyl-geranylacetone (GGA), originally used as an antiulcer agent, induces HSP synthesis in tissues, including the myocardium, through the activation of heat shock transcription factor-1 (HSF-1). ${ }^{46}$ Because GGA has protective effects on tachypacinginduced structural remodeling in several experimental models, HSP induction by GGA may help to treat or prevent clinical AF. ${ }^{46}$ It will also be important to determine if HSP-inducing drugs such as GGA are effective in preventing AF progression in patients.

A novel role for histone deacetylase-6 (HDAC6) has been reported in the maintenance of atrial myocyte proteostasis. ${ }^{43}$ Analysis of atrial tissues from patients with permanent AF, tachypaced atrial myocytes, and other experimental model systems, revealed HDAC6induced tubulin deacetylation, degradation of a-tubulin networks, and contractile dysfunction. These processes were prevented by the HDAC6 inhibitor tubastatin A. ${ }^{43}$ Taxol, a microtubule stabilizer, has been shown to suppress Reactive oxygen species (ROS) production and $\mathrm{AF}$ in an in vitro model system. ${ }^{47} \mathrm{It}$ is intriguing to note that colchicine, which depolymerizes tubulin, has been reported to reduce the incidence of both perioperative $\mathrm{AF}$ and $\mathrm{AF}$ recurrence after ablation. Tempering these findings, the recently reported COlchicine for Prevention of the Post-pericardiotomy Syndrome and Post-operative Atrial Fibrillation (COPPS-2) trial ${ }^{48}$ failed to meet its primary end-point of a reduction in postoperative AF based on an intent-to-treat analysis. However, this may have been due to treatment-induced gastrointestinal side effects, as a prespecified analysis of those on treatment found colchicine to be effective. ${ }^{49,50}$

\section{Key knowledge gaps}

1. What is the appropriate role for atrial selective ion channel modulators, antioxidants, and/or redox active agents in the treatment/prevention of AF?

2. Do profibrotic factors produced in other organs impact the atria? Does the opposite interaction occur?

3. How late can fibrosis-related atrial conduction abnormalities be reversed? Moreover, can these changes be reversed if the underlying hemodynamic abnormalities have been treated (by controlling BP, repairing valve function, treating HF, etc)?

4. Can modulators of the proteostasis or microtubule networks protect atrial function and/or reverse atrial dysfunction?

Heart Rhythm. Author manuscript; available in PMC 2015 May 08. 


\section{Genetic/genomic insights into the mechanisms of human AF}

Progress in characterizing the genetic loci associated with AF risk has been recently reviewed. ${ }^{51}$ In 2007, the first genome-wide association study (GWAS) of AF identified a single locus on chromosome 4q25 near the PITX2 gene that was strongly associated with AF. More recent studies have increased resolution by increasing the number of genotyped patients through the creation of global consortia. In addition to the $4 \mathrm{q} 25$ region, 8 additional AF-associated loci have been identified. The top genetic variants at these AF susceptibility loci are associated with a 5 -fold gradient in AF risk. ${ }^{51}$ Identified genetic loci implicate candidate genes that encode transcription factors related to cardiopulmonary development, cardiac-expressed ion channels, and cytoskeletal/nuclear envelope proteins. ${ }^{51}$ Much work is ongoing in this area, and many additional studies are still required to identify causal genetic variants, the mechanisms linking the variants to AF risk, and the cellular signaling pathways that mediate the risk of AF associated with the genetic variants. These studies are likely to provide fundamental insights into the mechanisms that underlie atrial ectopy and the transcriptional changes that occur with electrical/structural remodeling that increases risk of AF. Genetic analyses may also improve AF/stroke risk stratification and, in the future, help to guide patient-specific treatment.

\section{Key knowledge gaps}

1. By what mechanisms do genetic variants associated with $A F$ promote atrial ectopy and/or substrate changes?

2. Can genetic markers predict response to therapy, including preventive therapies?

3. Can genetic data enhance prediction of AF and be successfully incorporated into risk prediction tools?

\section{AF risk prediction}

AF risk factors include, but are not limited to, hypertension, obesity, HF, coronary atherosclerosis (CAD), valvular heart disease, thyroid disease, excessive alcohol intake, and family history of AF. ${ }^{52}$ Recently published risk prediction instruments have been derived in individuals of European and African ancestry and validated in 2 separate European cohorts. ${ }^{53,54}$ The risk scores include age, race, height, weight, systolic and diastolic BP, current smoking, use of antihypertensive medication, diabetes, and history of myocardial infarction and $\mathrm{HF}$, and have acceptable discrimination and calibration. ${ }^{55}$ Additional putative AF risk factors include anatomic and physiologic assessments of structural heart disease, biomarkers, ${ }^{56}$ and genetic markers ${ }^{57}$ For clinical utility, a novel marker must improve risk reclassification. Thus, although the inflammatory marker $\mathrm{C}$-reactive protein is associated with incident AF, it does not significantly enhance risk prediction. ${ }^{58}$ However, NPs do improve risk prediction. ${ }^{59}$ Similarly, a recent report suggested that single nucleotide polymorphisms can enhance AF risk prediction and reclassification. ${ }^{57}$ Characteristics of optimal risk markers have been established. ${ }^{60}$ Novel elements considered in future AF risk prediction models require rigorous testing to ensure that they substantively improve risk prediction, have adequate calibration, and enhance risk reclassification in both discovery and replication cohorts. Development of accurate risk prediction tools is an important first step in the effort to prevent AF. 


\section{Key knowledge gaps}

1. Can existing risk prediction tools be improved and validated in prospective studies to yield a simple, yet highly predictive model for risk of incident AF?

2. Does incorporation of additional clinical characteristics, physiologic measures, and genomic factors improve risk prediction in a useful and usable manner?

3. Can prospective use of risk prediction tools enhance AF prevention or better direct $\mathrm{AF}$ treatment to limit progression to persistent AF?

\section{Advancing AF prevention efforts by focusing on risk modification}

Early identification and treatment of modifiable risks factors is a critical step toward primary prevention of AF. Estimates suggest that $\sim 57 \%$ of AF can be attributed to hypertension and other modifiable risk factors. ${ }^{61}$ Although there are additional modifiable AF risk factors, here we focus on hypertension, obesity/diabetes, HF, and sleep apnea as prevalent and important targets for primary prevention of AF. The relationships among these risk factors are outlined in Figure 2.

Secondary prevention of AF recurrence should similarly include efforts to optimize weight, control BP, and diagnose and treat sleep apnea. Controlled interventions compared to usual care are instructive, and risk reduction programs following AF ablation could become standard medical management practice. Creation and evaluation of "post-AF ablation rehab" programs in which patients are followed for several months after ablation and intensively counseled on BP control, dietary issues, and sleep apnea recognition and treatment should be a priority. Although these factors have been independently associated with risk of AF recurrence, the impact of their treatment on AF incidence and burden has not yet been collectively or systematically addressed. Such efforts are strongly encouraged.

\section{Hypertension}

Hypertension promotes left ventricular (LV) dysfunction, LA dilation, and cardiac fibrosis. A recent study demonstrated that hypertension promotes heterogeneous conduction and repolarization. Additionally, hypertension promotes dilation of the PVs and abbreviation of PV tissue refractoriness, ${ }^{62}$ especially in patients with pAF. Effective treatment of hypertension has been associated with a reduction in LV mass and decreased incidence of new-onset AF. ${ }^{63}$ Early and effective BP control is a logical early target for primary prevention of AF; however, there are several challenges. These challenges for primary prevention include (1) identification of whom to treat and when to begin, (2) a lack of consensus about the most effective treatments, (3) a lack of provider adherence to guidelines for hypertension therapy, (4) an inability to monitor BP in "real time," and (5) an inability to identify asymptomatic hypertensive individuals prior to the onset of AF.

Aggressive screening using clinical risk prediction tools can help to identify those who would benefit the most from treatment to prevent complications of hypertension, including atrial remodeling. Home BP monitoring to evaluate the efficacy of treatment is under investigation. ${ }^{64}$ Although AF is not being evaluated as an end-point, drug compliance and efficacy studies will yield important data. Development of easier to use, more "real time" or 
even continuous ambulatory BP monitoring devices would constitute a significant advance that would enhance identification and improve management of hypertension.

Which antihypertensive approaches are best for preventing AF?: A-II promotes sympathetic nervous system activity, systemic oxidant production, systemic and atrial inflammation, development of atrial fibrosis, gap junction uncoupling, impaired atrial $\mathrm{Ca}^{2+}$ handling, and ion channel remodeling. ${ }^{65}$ Although studies of RAAS inhibition have been disappointing for the prevention of recurrent AF, metaanalyses of patients with $\mathrm{LV}$ hypertrophy or LV dysfunction suggest that use of ACEI/ARBs can prevent 20\%-30\% of new-onset AF events. ${ }^{66}$ ARBs may be superior to $\beta$-adrenergic receptor blocker therapy for primary AF prevention. In the Losartan Intervention For Endpoint reduction in hypertension study (LIFE) randomized trial, new-onset AF was significantly reduced by use of losartan vs atenolol in patients with LV hypertrophy. ${ }^{67}$ Similarly, in hypertensive patients without structural heart disease, ACEI/ARBs were more effective in preventing AF than $\beta$-blockers and diuretics. ${ }^{68} \mathrm{ARBs}$ may be useful adjuncts to amiodarone in preventing AF recurrence following DC cardioversion in patients with persistent AF. ${ }^{69}$ However, as monotherapy, the impact of RAAS blockade on secondary AF prevention has been mixed, perhaps related to the timing of ACE/ARB therapeutic initiation ${ }^{70,71}$ and the antecedent presence of hypertension. Relative to A-II, less attention has focused on the role of aldosterone in AF. Upstream of A-II, aldosterone also promotes atrial oxidative stress, inflammation, fibrosis, and structural/electrical remodeling. In the setting of hypertension and/or HF, aldosterone antagonists warrant greater evaluation as a strategy to prevent $\mathrm{AF}$ or limit its progression. ${ }^{72}$ Assessment of AF incidence and burden as secondary outcomes in prospective studies of novel antihypertensive drugs is still strongly encouraged. ${ }^{1}$

What is the role for renal sympathetic denervation?: Pharmacologic control of BP is limited by patient compliance, underrecognition of adequate control, and the presence of drug-resistant hypertension. ${ }^{73}$ Renal sympathetic denervation (RSD) has been suggested as a strategy to simultaneously address both compliance and drug-resistance issues, but a recent well-designed and conducted study (Symplicity-3) failed to demonstrate a benefit of RSD when compared to a sham-procedure, medically treated control group. ${ }^{74}$ The results of the Symplicity-3 study are limited by the failure to assess whether the renal nerves were effectively denervated. A meta-analysis of small studies in which the impact of concomitant RSD in AF patients undergoing pulmonary vein isolation (PVI) suggests a potential benefit of the procedure in patients with resistant hypertension. ${ }^{75}$ The future of RSD as a primary antihypertensive or anti-AF therapy is currently uncertain, in part due to the lack of a clearly defined acute end-point of RSD. Appropriately powered randomized controlled trials (RCTs) with sham controls are needed to clarify the value of this approach.

\section{Key knowledge gaps}

1. What is the optimal approach for monitoring $\mathrm{BP}$ in patients at risk for $\mathrm{AF}$ ?

2. Which antihypertensive treatment is best for preventing AF?

3. What, if any, is the role of RSD in the prevention of AF in hypertensive patients? 


\section{Obesity/diabetes}

Obesity impacts many aspects of health, including AF risk. Obese individuals are $\sim 2.5$-fold more likely to develop AF than nonobese individuals, ${ }^{76}$ and increased body mass index (BMI) is associated with increased risk for postoperative AF after cardiac surgery. ${ }^{77}$ Obesity is incorporated in the Framingham AF risk assessment tool, ${ }^{54}$ and AF risk is greatest for individuals with central obesity. Interestingly, elevated weight and $\mathrm{HbA1c}$ levels are associated with greater risk of developing persistent (rather than paroxysmal) AF. ${ }^{78}$

Experimental studies provide insight into how obesity promotes AF. In a sheep overfeeding model, increasing weight was associated with increased mean arterial pressure and LA pressure, ${ }^{79}$ leading to progressive increases in LA and right atrial volumes. Conduction slowing, heterogeneity, and delayed activation were also apparent. Rate-dependent conduction slowing was greater in obese than in overweight or control animals. Moreover, increased weight was associated with increasing frequency of spontaneous AF episodes, and the number and duration of inducible AF episodes. Increased weight has also been associated with inflammation, increased concentrations of profibrotic signaling molecules, and the development of atrial fibrosis. ${ }^{79}$ Taken together, these data suggest that obesity increases AF susceptibility and burden.

From the perspective of prevention, it is critical to determine whether weight loss is sufficient to decrease AF risk or burden. A recent study assessed the impact of weight loss on AF burden and severity in 150 overweight/obese patients with symptomatic AF. ${ }^{80}$ Patients were randomized to either an intensive weight loss intervention or a general lifestyle (control) group. Lipids, glucose, and BP were carefully monitored and managed in both groups. At 12-month follow-up, BMI and waist circumference decreased more in the intervention than in the control group, as did AF symptom burden and severity. ${ }^{80}$ Efforts to replicate and extend this study to other populations are warranted.

In addition to obesity, hypoglycemia in individuals with type 2 diabetes mellitus (T2DM) can provoke ectopy, bradycardia, and AF. ${ }^{81}$ In an observational study of 25 insulindependent T2DM individuals with at least 2 other cardiovascular risk factors for AF (hypertension, dyslipideia, smoking, obesity), blood glucose and cardiac electrical activity were continuously monitored for 5 days. Atrial ectopy was 4-fold higher and bradycardia 8fold higher during nocturnal hypoglycemia than during euglycemia, but neither was different during the daytime. ${ }^{81}$ Autonomic and metabolic factors are highly interrelated, and both contribute to AF risk.

Given the global rise in the prevalence of obesity and diabetes, aggressive efforts are needed to promote healthy eating, regular physical activity, ${ }^{5}$ and weight control while monitoring/ managing diabetes, lipid levels, and hypertension. These efforts may significantly reduce AF risk. Likewise, in secondary prevention, similar efforts may reduce AF symptom burden, and episode frequency and duration. Future research should also assess the burden of asymptomatic AF in relation to modification of risk factors. Success in these goals would likely also reduce the risk of stroke and HF. These efforts will require the collective education and collaborative efforts of heart rhythm professionals, cardiologists, general practitioners, nurses, educators, and the public. 


\section{Key knowledge gaps}

1. Can reversal of cardiometabolic risk factors reduce the incidence of $A F$ in patients with $\mathrm{AF}$ (ie, secondary prevention) or prevent $\mathrm{AF}$ altogether (primary prevention)?

2. What is the relationship of age to the reversibility of cardiometabolic risk factors?

3. Does weight loss reverse the fibrotic/hypertrophic atrial remodeling observed in obesity? Does the nature of the diet (or intervention) under which weight is lost affect the durability of weight loss or atrial remodeling?

4. What molecular pathways underlie obesity related atrial remodeling?

5. What are the most effective/efficient ways to achieve durable weight loss?

6. What mechanisms link nocturnal glucose regulation with autonomic activity and atrial ectopy?

\section{Heart failure}

Like AF, HF is a burgeoning epidemic, affecting more than 5 million individuals in the United States. HF patients have an increased risk of developing AF, due to both underlying cardiovascular disease and the remodeling and hemodynamic impairment associated with $\mathrm{HF}$ syndromes. The prevalence of AF in those with HF ranges from $4 \%$ to $40 \%$ as the degree of symptomatic impairment increases and thus is 4- to 40-fold greater than the background population rate. ${ }^{82}$ Patients with either systolic or diastolic dysfunction are at increased risk of AF. Although AF is common in HF patients, fewer antiarrhythmic drugs (AADs) are safe in HF patients compared to those without structural heart disease. ${ }^{83}$ Only 2 antiarrhythmic drugs AADs are guideline-recommended in HF patients (amiodarone and dofetilide), and both have limiting adverse effects. Amiodarone leads to end-organ toxicities, and dofetilide has significant proarrhythmic risk. Catheter ablation is a promising therapy in patients with $\mathrm{AF}$ and concomitant $\mathrm{HF}$, but recurrence rates may be higher. Thus, as with most cardiovascular disorders, the most effective treatment strategy for patients with $\mathrm{AF}$ and HF would be prevention.

Some components of optimal medical therapy for HF may reduce the risk of new-onset AF. Aldosterone antagonists, including aldosterone and eplerenone, may prevent $\mathrm{AF}$ in $\mathrm{HF}$ patients. ${ }^{84,85}$ Additionally, in HF patients who are $\beta_{1}$-adrenergic receptor $389 \mathrm{Arg}$ homozygotes, bucindolol may prevent new-onset AF. ${ }^{86}$ The Genetically Targeted Therapy for the Prevention of Symptomatic Atrial Fibrillation in Patients With Heart Failure (GENETIC-AF) trial is being conducted to evaluate the efficacy of genotype directed bucindolol (NCT 01970501). It seems logical that effective HF treatment may lower the incidence of new-onset AF. Thus, emerging HF therapies may have an important role in the prevention of $\mathrm{AF}$, and the incidence of $\mathrm{AF}$ should be included as an outcome measure in current and planned HF clinical trials.

\section{Key knowledge gaps}

1. Does aldosterone inhibition prevent new-onset $\mathrm{AF}$ in patients with $\mathrm{HF}$ ? 
2. Can genotype-directed therapy be used to guide prevention of AF in patients with HF?

3. Can emerging pharmacotherapies for HF reduce the risk of AF?

4. What is the best method of secondary prevention for AF in patients with HF? What is the best catheter ablation strategy in patients with HF?

\section{Sleep disordered breathing}

Sleep disordered breathing (SDB) afflicts more than $15 \%$ of adults and $30 \%-50 \%$ of cardiovascular disease (CVD) patients. SDB causes intermittent hypoxia, intrathoracic pressure swings, and altered preload and afterload. Autonomic imbalance during SDB occurs via increased vagal activity during apnea/hypopnea (AH) episodes and hypercarbia/ hypoxia-induced sympathetic nervous system activation after $\mathrm{AH}$ episodes.

Epidemiologic studies document a strong association of SDB with AF (odds ratio 2-4), even after accounting for obvious confounding factors (age, BMI, hypertension, self-reported HF). ${ }^{87}$ Different mechanisms underlie central sleep apnea (CSA) vs obstructive sleep apnea (OSA). Among the elderly, stronger associations have been reported between AF and CSA compared to OSA. Moderate to severe SDB (AH index 224) conferred the greatest risk of AF. ${ }^{87}$ Male gender, hypertension, and diabetes are apparent risks for AF in SDB, and, based on cardiac magnetic resonance imaging (MRI), SDB is associated with greater right ventricular volume and LV mass and larger LA dimensions. ${ }^{88}$

Figure 3 summarizes some of the downstream consequences of SDB that likely contribute to AF risk. Although continuous positive airway pressure (CPAP) reduces AF recurrence after ablation and cardioversion in those with SDB, existing data are limited by retrospective design and intrinsic biases of potential nonadherence with other aspects of medical care in those declining CPAP treatment. ${ }^{89-91}$ A logical primary AF prevention RCT would assess the impact of SDB treatment on AF outcomes. Future research into SDB and AF should collect objective cardiac function data as well as measurement of autonomic function and markers of systemic inflammation and oxidative stress. Holter recording of both daytime and nocturnal ECGs would help to clarify SDB pathophysiology.

Large, adequately powered, prospective longitudinal studies are needed to rigorously identify the class and severity of SDB and assess the temporal relationships of SDB and its determinants to incident $\mathrm{AF}$ development. These studies would facilitate characterization of subgroup susceptibilities to SDB and AF in terms of age, sex, race, underlying cardiac disease, and genetic variation. This would facilitate early identification of vulnerable groups that could be intensively targeted for AF screening and prevention.

\section{Key knowledge gaps}

1. What is the impact of $\mathrm{SDB}$ as a relevant exposure in ongoing and planned $\mathrm{AF}$ clinical research?

2. In planned RCTs, what is the impact of SDB treatment on AF outcomes? 
3. What is the additive predictive value of SDB indices to $\mathrm{AF} /$ stroke risk prediction algorithms?

\section{Prevention of AF recurrence, progression, and sequelae}

In the cases where $\mathrm{AF}$ is established, better treatments that prevent $\mathrm{AF}$ recurrence or reduce its burden may decrease the incidence of stroke and/or the development of cardiomyopathy/HF. Given the poor efficacy of antiarrhythmic drug therapy and limited efficacy of catheter ablation in persistent forms of AF, early interventions that terminate $\mathrm{AF}$ or prevent the progression of AF may have significant clinical benefit. Research in several areas is needed to advance these goals.

\section{Imaging}

Functional imaging of the atria-Electroanatomic mapping and imaging of the atria have evolved from preclinical use of electrode arrays and optical imaging. This evolution has led to the routine clinical use of percutaneously deployed arrays that record unipolar and bipolar electrograms and propagation characteristics from their temporospatial distribution on the millimeter scale. Optical mapping uses voltage- or $\mathrm{Ca}^{2+}$-sensitive dyes to derive action potential and propagation characteristics on the submillimeter to millimeter scale. These tools continue to produce new insights and functional information..$^{92}$ ECG-based imaging is currently leading the way in clinical application of noninvasive activation mapping, but other technologies are also under development.

Myocardial scar and fibrosis are important barriers that disrupt wavefront propagation, create anisotropy, and promote reentry. Noninvasive imaging of scarred atrial myocardium demonstrates various correlations with overall scar burden, including both duration of AF and outcomes following catheter ablation. ${ }^{93}$ Imaging of atrial scar/fibrosis may enhance risk stratification and patient selection for $\mathrm{AF}$ ablation. Using late gadolinium enhanced cardiac magnetic resonance imaging (LGE-CMR) to detect scar, the DECAAF study has confirmed the relationship between delayed myocardial enhancement and risk of recurrence of $\mathrm{AF}$ after ablation. ${ }^{94}$ However, LGE-CMR operates at the limits of resolution dictated by the biophysics of MRI and operator expertise, and objective and automated measurement of enhancement and the ability to correlate point-by-point enhancement with local electrophysiologic characteristics ${ }^{95}$ have not been adequately developed to the point that LGE-CMR can be reliably used to identify arrhythmogenic sources or targets for sitespecific treatment delivery. Additionally, MRI has been used to define ablated tissue in patients who have undergone ablation; however, there are challenges in differentiation of scar from atrial fibrosis vs scar from ablation. As MRI and other techniques emerge and mature, electroanatomic mapping will remain an important part of validation of new imaging techniques. Research developing more sensitive and reliable techniques to detect atrial scar/fibrosis is still needed.

Validation of methods for noninvasive imaging of AF-The 12-lead ECG has limited ability to identify AF mechanisms or to localize atrial arrhythmias. Development of electroanatomic mapping systems has transformed $\mathrm{AF}$ treatment and provided tools to help understand the mechanisms of atrial arrhythmogenesis. Refinement of both the mapping 
tools and the mechanistic insights into $\mathrm{AF}$ are pointing toward the importance of wide area (panoramic) contact mapping of fibrillatory wavefronts. ${ }^{96}$ While focal mapping strategies focus on the scatter of localized electrograms, wavelets and voltages, ${ }^{97}$ wavefronts that are critical to the arrhythmia identified by contact mapping ${ }^{96}$ may theoretically involve sufficient cardiac mass to be resolved from the body surface ${ }^{92}$ using similar concepts and approaches to the "inverse solution" currently used in noncontact endocardial mapping. ${ }^{98}$ This provides motivation for further refinement of noninvasive electrocardiographic activation mapping from the body surface. ${ }^{92}$

There are now early reports of the clinical use of electrocardiographic mapping (ECM), ${ }^{99} \mathrm{a}$ 3D surface ECG-based noninvasive epicardial mapping system that provides simultaneous global chamber mapping derived from a 252-electrode vest applied to the patient's torso. The precise electrode positions and juxtaposition with the heart are derived from a noncontrast thoracic CT scan that provides high-resolution images of the heart and the vest electrodes in situ. ECM has been used to noninvasively reconstruct nonfibrillatory atrial arrhythmias, with a high diagnostic accuracy ${ }^{100}$ in a small series of patients with AF. ECM provides only epicardial mapping, precluding direct mapping of the endocardium or the septum. AF and AT with a low signal-to-noise ratio on the torso pose analytic challenges, particularly during high ventricular rates or in the absence of reliable QRST-subtraction algorithms. ${ }^{99}$ The impact of ECM on procedure times, fluoroscopic exposure, and the efficacy of ablation of atrial arrhythmias seems promising but requires systematic assessment.

\section{Key knowledge gaps and research needs}

1. Develop better, reliable, and reproducible techniques for imaging atrial scar and fibrosis.

2. Validate body surface mapping and determine its utility in guiding treatment of AF.

3. Improve technologies associated with panoramic $\mathrm{AF}$ wavefront imaging, particularly in patients with advanced forms of AF.

\section{Nonpharmacologic treatment of AF}

AF mapping/ablation-Mapping and ablation are important tools and therapies for secondary AF prevention, but current strategies still yield suboptimal results that result in frequent early and late $\mathrm{AF}$ recurrence. In recent multicenter trials, 1-year ablation success rates were $50 \%$ to $70 \%$ (single to multiple procedures) in $\mathrm{pAF},{ }^{82}$ with much lower success rates in patients with persistent $\mathrm{AF}$ or with comorbidities such as untreated SDB and/or hypertension. Important knowledge gaps include how to prevent AF recurrence in more patients early (first year) after ablation ${ }^{82}$ and over the longer term, because AF can recur late (eg, several years or more) following ablation. Better tools and techniques are needed to achieve durable PVI, ${ }^{82}$ including an enhanced understanding of AF mechanisms and more patient-specific identification of ablation targets. Identification of the factors that contribute to the development and progression of $\mathrm{AF}$ at the individual level will be critical for success. Cohort studies that incorporate biomarkers, genomics, and electroanatomic imaging with 
clinical parameters may guide development of more personalized approaches to ablation technique and improve subsequent outcomes. ${ }^{101}$

Achieving durable PVI remains technically challenging. ${ }^{82}$ Cardiac MRI (cMRI) studies show that nontransmural lesions can cause inflammation that initially appears to acutely result in PVI but permit recurrent conduction once the edema subsides. ${ }^{102}$ Gaps as small as $1.5 \mathrm{~mm}$ may permit electrical reconnection between the LA and PVs. ${ }^{103}$ Future studies should evaluate whether real-time cMRI, other imaging modalities, or pharmacologic challenge ${ }^{104}$ can distinguish permanent from functional block, to indicate when additional ablation is required at the initial procedure. Two ongoing trials (NCT01490814, NCT01824394) are testing the hypothesis that tissue ablation can be enhanced by using cryoballoon ablation rather than standard radio-frequency ablation. Additional trials (NCT01693120, NCT01824394) are evaluating the use of circular ablation catheters and different mechanisms of current delivery to improve radiofrequency ablation and PVI. Development of alternate energy sources (eg, LASER), catheters that provide direct visualization of ablated tissues, and use of real-time contact-force sensing to ensure consistent lesion delivery may also improve procedural efficacy.

There is a need to identify individualized mechanism-based ablation targets. Future studies should include mapping of non-PV triggers, which can emerge after PVI to cause AF recurrence and may be challenging to map. ${ }^{105}$ It is unclear which techniques can be used to identify infrequent ectopic triggers and what end-points should be used for their ablation. Recent approaches to empirically ablate "typical" trigger sites ${ }^{106}$ should be compared against patient-specific mapped non-PV triggers. ${ }^{105}$

AF substrate ablation may prevent AF recurrence if PVs reconnect or non-PV triggers emerge. ${ }^{82}$ Substrate targeting may be central for effective treatment of persistent AF and increasingly important in pAF cases in which structural remodeling and fibrosis, electrical remodeling, and conduction slowing ${ }^{107}$ are significant. Defining substrate has been difficult, and the results with adjunctive ablation in clinical trials have been mixed. Although AF is a disorganized rhythm, several studies now conclude that this disorganization may result from organized sources (rotors or focal sources), ${ }^{96}$ as originally demonstrated in animal models. ${ }^{108}$ Early results from clinical studies suggest that ablation of focal sources improves out-comes. ${ }^{96}$ This contrasts with the alternative viewpoint that complex activity per se may cause AF without underlying drivers. ${ }^{109}$ Efforts to resolve the mechanistic origin and significance of rotors in AF are warranted.

Autonomic activity is mediated by discrete ganglionated plexi (GP) on the atrial epicardium. ${ }^{110}$ It alters global spatial gradients of repolarization and may influence localized or nonlocalized mechanisms. Intrinsic cardiac autonomic nerve activity precedes the onset of AF in ambulatory dogs, ${ }^{111}$ and it has been suggested that ablation of GP with surgical or catheter-based techniques might be effective in controlling AF. A recent RCT suggests that GP ablation may be a useful adjunct to PVI. ${ }^{112}$ Efforts to replicate this observation are warranted, with careful short- and long-term ECG monitoring of procedural efficacy and procedural side effects. 
New approaches to mapping and ablation may target regions of oscillating action potential duration (APD) that can cause wavebreaks leading to AF. ${ }^{113}$ Better approaches are needed to map atrial repolarization dispersion ${ }^{114}$ and to determine whether it is related to autonomic innervation. ${ }^{112}$ Conduction slowing is common in AF patients ${ }^{115}$; at rapid rates, this may initiate AF. ${ }^{115}$ Imaging studies (delayed enhancement MRI ${ }^{93}$ or other approaches) may help to assess the mechanisms underlying conduction slowing and guide the choice of pharmacologic interventions to slow/reverse the development of atrial fibrosis.

\section{Key knowledge gaps}

1. Can ablation of rotors or non-PV triggers improve long-term success rates after PVI?

2. Can imaging-guided substrate modification improve ablation outcomes in patients with persistent forms of $\mathrm{AF}$ ?

3. Will alternative energy sources or contact force sensing improve PVI durability, long-term freedom from AF, and procedural safety?

4. Can therapies targeted at preserving atrial conduction velocity prevent AF?

5. Can more detailed understanding of AF mechanisms help target ablation and improve both the effectiveness and safety of AF ablation?

Device-based monitoring-Transcutaneous and implantable monitoring devices can screen for AF and categorize AF burden. It is increasingly likely that these devices will have a role in monitoring responses to pharmacologic and ablation therapies. Twice-daily, community-based handheld ECG monitoring was effective in detecting silent $\mathrm{AF},{ }^{116}$ and subclinical AF detected by pacemakers has been identified as a risk factor for stroke. ${ }^{117}$ Given the burden of unrecognized or silent $\mathrm{AF},{ }^{118}$ it will be important to develop costeffective approaches to screen for atrial ectopy, subclinical AF, and clinical AF in the community. New devices capable of prolonged ECG recording (weeks to years) could facilitate natural history studies, diagnosis, prognosis, and assessment of response to therapy. These technologies may enable rigorous assessment of the predictive power of PACs on the development AF, assessing the interaction of PAC burden with electrocardiographic measures of autonomic status and P-wave morphology. They may also offer the ability to detect arrhythmia precursors to sustained AF in patients at increased risk of stroke ${ }^{117}$ and to resolve whether and when AF occurs in clusters. ${ }^{119}$ Monitoring could provide insights into whether/how cerebral embolic events are temporally related to AF. These important questions may be addressed with devices available now or in the very near future.

Another unresolved question is whether monitoring can empower or motivate patients to participate more actively in their own care. Evidence is accumulating with respect to the benefits of patient self-monitoring for a variety of chronic conditions, including obesity and BP. Patient self-monitoring of BP yields improved outcomes, at least in short-term followup. ${ }^{120}$ This is relevant with respect to concerns about workforce gaps for cardiovascular care and the sustainability of integrating extensive self-monitoring or continuous physiologic

Heart Rhythm. Author manuscript; available in PMC 2015 May 08. 
data into clinical workflows. ${ }^{121}$ Bluetooth ECG transmission to smartphones or other personal digital devices might serve as prompts to change medication or to seek medical attention if AF persists. ${ }^{122}$ Finally, prolonged monitoring may help to quantitatively assess and compare the efficacy of various therapies.

\section{Device-based therapies}

Atrial pacing: The effects of atrial pacing strategies on AF prevention have been systematically reviewed. ${ }^{123}$ Briefly, considerable efforts over the last 25 years to develop pacing therapies for preventing or treating $\mathrm{AF}$ have not identified effective pacing strategies. This conclusion is based on both observational and RCTs. In contrast, there is strong evidence that minimizing ventricular pacing at the expense of atrial pacing in patients with bradycardia prevents the appearance of symptomatic AF. ${ }^{124}$

Device-triggered therapy: While pacing approaches appear largely ineffective, devices are playing a growing and key role in detecting and treating $\mathrm{AF}$ and preventing cerebral thromboembolism. For example, the recent CRYSTAL AF trial demonstrated that implanted loop monitoring in patients with cryptogenic stroke results in improved detection of AF and subsequent anticoagulation. ${ }^{125}$ The role of monitoring devices for targeted use of rapidly acting oral anticoagulants (OACs) upon detection of intermittent $\mathrm{AF}$ is also being studied (NCT01706146).

Device-based autonomic modulation: Autonomic nerve activity is an important AF trigger; its role in the pathophysiology and treatment of AF has recently been reviewed. ${ }^{126}$ Autonomic nerve activity may be a target for both direct and indirect therapeutic intervention/modulation. ${ }^{1}$ Devices that provide safe, effective, and targeted autonomic modulation that are easily controlled and do not cause nerve damage may represent a valuable therapeutic intervention. Parasympathetic activity, typically mediated by vagal nerves, can suppress sympathetic stimuli at pre- and postsynaptic levels. ${ }^{126}$ Baroreflex stimulation devices have been shown to prevent hypertension by suppressing sympathetic nerve activity. ${ }^{127}$ Direct cervical vagal nerve stimulation has been reported to attenuate development of $\mathrm{HF}$ in dogs, rats, and humans. ${ }^{126}$ At stimulus strengths that did not reduce heart rate, low-level vagal nerve stimulation suppressed AF induction in dogs subjected to intermittent rapid atrial pacing. ${ }^{126}$ Remodeling secondary to vagal nerve stimulation may attenuate sympathetic nerve activity and AF inducibility. Skin is well innervated by autonomic nerves. Recent small studies suggest that neuromodulation through skin or subcutaneous tissues may also help to control AF using either a transcutaneous approach ${ }^{128}$ or acupuncture. ${ }^{129}$ Further studies are required to determine if these novel methods will be clinically useful.

\section{Key knowledge gaps}

1. Can device-based screening for $\mathrm{AF}$ improve stroke prevention and downstream clinical outcomes?

2. Can autonomic modulation meaningfully reduce $A F$ recurrence or prevent $A F$ in those at high risk? 


\section{AF-related stroke prevention}

\section{Brain imaging}

Given the impact of AF on stroke and the association of AF with cognitive dysfunction, ${ }^{130}$ brain imaging may improve the care of AF patients. Brain imaging can help to stratify stroke risk in AF patients. Presence of subclinical brain infarcts is robustly associated with the subsequent risk of stroke. Short-term risk of stroke after transient ischemic attack (TIA) was 3-fold higher in patients with a brain infarct on MRI compared to those without. ${ }^{131}$ As existing clinical stroke risk prediction scores are imperfect in delineating stroke risk, ${ }^{132}$ use of brain imaging may significantly improve stroke risk stratification in patients with AF.

Brain imaging may also assist in stratifying risk of intracerebral hemorrhage in patients being considered for anticoagulant therapy and serve as a surrogate marker of stroke that could improve the efficiency of clinical trials for prevention of thromboembolism in AF. ${ }^{133}$ Surrogate end-points are not appropriate for all trials, but their selective use may facilitate exploratory trials that are currently impossible. This strategy may be helpful in AF.

In $\mathrm{AF}$ patients undergoing radiofrequency ablation procedures, many patients have evidence of asymptomatic cerebral emboli visible on postprocedural MRI brain scans. ${ }^{134}$ Lowering the peak energy delivered during the ablation procedure or intensifying anticoagulation may reduce the incidence of these emboli, at the cost of increased procedural time. ${ }^{134}$ Further study of brain imaging may help to evaluate the significance of these emboli and to reduce their incidence.

\section{Pharmacologic advances in AF-related stroke prevention}

Since 2009, 4 non-vitamin K-dependent oral anticoagulants (NOACs) that selectively inhibit either thrombin (dabiga-tran) or factor Xa (rivaroxaban, apixaban, edoxaban) have been evaluated for stroke prevention in AF. ${ }^{135}$ Compared to warfarin, NOACs offer relative efficacy, safety, and convenience. Warfarin efficacy and safety depend on the quality of anticoagulation control, as reflected by the average time in therapeutic range (TTR). Due to the difficulty of achieving therapeutic international normalized ratios (INRs) quickly after starting warfarin, an increased risk of stroke has been observed in the 30 days after initiation of warfarin. ${ }^{136}$ Given the availability of NOACs and the recognition that well-controlled anticoagulation with warfarin offers high efficacy and safety, there is an evolving clinical practice shift in which the risk threshold for treatment is being lowered. There is increasing focus on identifying patients at very low risk of stroke-those under 65 years old with AF in the absence of other risk factors, in whom OAC is not indicated.

For the patients who do require OAC therapy, questions remain. Undertreatment with warfarin is common, with $30 \%-50 \%$ of "high-risk" AF patients not receiving anticoagulation. ${ }^{137}$ The causes for this practice need to be better understood through population-based studies and registries. Some investigators advocate a need to identify the newly diagnosed AF patients who are likely to do well on warfarin (with high TTR). A recent ESC position document recommends that use of the $\mathrm{SAMeTT}_{2} \mathrm{R}_{2}$ score $^{138}$ be considered to help identify newly diagnosed, warfarin-naïve AF patients who would do less well on warfarin (poor TTR; if $\mathrm{SAMeTT}_{2} \mathrm{R}_{2}$ score $>2$ ) and who would require additional 
interventions to achieve acceptable anticoagulation control, or be best initially treated with a NOAC instead of warfarin. ${ }^{139}$ This score seems predictive of labile INRs and consequently more thromboembolism, bleeding, and death. ${ }^{140}$

An unresolved issue requiring clinical evaluation is the lack of direct comparisons between the 4 NOACs for the AF population as a whole and/or for subpopulations at particularly high risk of stroke or bleeding. One such population is individuals with AF and impaired renal function, as all NOACs are at least partially excreted via the kidneys. ${ }^{135}$ Another is the group of patients with prosthetic valves.

\section{Cryptogenic stroke/endothelial dysfunction/thromboembolic risk prediction}

One-third of ischemic strokes are labeled "cryptogenic" because a definite cause cannot be established. Although clinically apparent AF is a well-established cause of cardioembolic stroke, clinically apparent AF is often preceded by subclinical AF, atrial ectopy, or other nonspecific atrial tachyarrhythmias. ${ }^{117}$ It is unknown when stroke risk begins during arrhythmia progression; evidence suggests that stroke can occur before the manifestation of clinically apparent AF. Even 6 minutes of subclinical AF has been associated with increased risk of subsequent ischemic stroke, in the absence of clinically apparent AF. ${ }^{117}$ Frequent atrial ectopy may correlate with increased stroke risk even among patients who have not yet developed AF. ${ }^{141}$ In cryptogenic stroke patients, ambulatory ECG monitoring to rule out subclinical AF often shows frequent atrial ectopy immediately after the stroke, progressing to AF within months. ${ }^{142}$ Many cryptogenic strokes likely result from subclinical AF not identified before stroke or during the stroke hospitalization. Observational studies using extended ambulatory ECG monitoring after stroke have found previously undiagnosed $\mathrm{AF}$ in many patients, up to $25 \%$ after several months of monitoring. ${ }^{142}$

\section{LA occlusion devices}

Devices to facilitate left atrial appendage (LAA) occlusion may become a safe, evidencebased method to prevent stroke. ${ }^{143}$ The merits of intravascular vs intrapericardial devices have not yet been assessed. Progress in this field has been sparked by the composite surgical experience attesting to the efficacy of LAA exclusion in preventing cerebroembolic events. Other intravascular occlusion and intrapericardial external LAA ligation devices are also being developed and studied. Critical evaluation of the long-term efficacy of these devices is warranted.

\section{Key knowledge gaps}

1. Does population-based screening for AF decrease stroke and improve survival?

2. Is population-based AF screening cost-effective?

3. What is the best method for AF detection and diagnosis in cryptogenic stroke patients?

4. Is antiplatelet therapy or OAC the most appropriate medical therapy for patients with cryptogenic stroke?

Heart Rhythm. Author manuscript; available in PMC 2015 May 08. 
5. Can risk stratification scores, such as $\mathrm{SAMeTT}_{2} \mathrm{R}_{2}$, be used to help select OAC therapy and improve outcomes, including bleeding and stroke?

6. Does NOAC therapy improve outcomes in nonvalvular AF patients who are at low risk of stroke (eg, $\left.\mathrm{CHA}_{2} \mathrm{DS}_{2}-\mathrm{VASc}=1\right)$ ? What is the optimal treatment strategy in these patients?

7. Can LAA closure technologies serve as a safe and effective alternative to pharmacologic stroke prevention?

\section{The need for innovative research structures and methods}

\section{Clinical trials in the era of financial constraints}

It is estimated that less than $15 \%$ of major recommendations from clinical practice guidelines in cardiovascular medicine are grounded in high-quality evidence, including those for AF treatment. ${ }^{7}$ The evidence gap will continue to widen unless the productivity and efficiency of the clinical research enterprise are improved. The current clinical trials system is encumbered by regulatory and administrative burdens. ${ }^{144}$ Trial startup is hampered by poorly coordinated institutional review board (IRB) activities, lack of standardized data collection (with limited reusability of case report forms), and institutionspecific contract requirements. Trial monitoring often uses retrospective evaluation rather than building quality into study design. ${ }^{145}$ Systemic improvements are needed to provide patients (with or at risk for $\mathrm{AF}$ ) with the evidence needed to optimize prevention, diagnosis, and treatment. Creation of AF-focused clinical research networks may improve AF trial design and increase likelihood of funding following competitive review. It is often possible to use a factorial design or a predefined substudy to address several questions within one trial. ${ }^{146}$ Some networks, such as the Canadian Heart Rhythm Society, provide a regular forum where investigators, particularly junior investigators, can propose study ideas and receive feedback from researchers and clinicians to help develop and implement their proposals. Networks can accelerate trial enrollment more than simply increase the number of sites.

In addition to a role for research networks, four key recent developments will enhance AF and related clinical research. First, electronic health records (EHRs) are becoming ubiquitous for basic data collection, as they are essentially mandatory in the United States due to federal meaningful use criteria. ${ }^{147}$ Data integration across EHRs will enable analysis of data in structured formats that facilitate analysis. Second, clinical registries are being used more effectively for clinical research. The potential for synergy between EHRs and registries is significant. Third, a "patient-centered" approach to data collection now complements the above-described EHR and registry networks. Both patient-reported outcomes and physiologic data captured directly from portable personal devices and wearable technologies are proliferating. Heart rhythm detection and monitoring devices are leading this effort and will impact AF research. In perhaps the most innovative approach, patients and their advocates are now being included in the research ecosystem. This is most visible in the Patient-Centered Outcomes Research Network (PCORnet). ${ }^{148}$ Not surprisingly, the greatest advocates for high-quality research are patients and their families.

Heart Rhythm. Author manuscript; available in PMC 2015 May 08. 


\section{Patient involvement in AF prevention research}

A recent insightful essay notes that "prevention needs to be connected to things people already value to make prevention a daily reality." 149 A central challenge in AF prevention and improving care is the translation of research findings to patient-centered clinical practice. The research priorities of clinical trials are not always concordant with patient priorities in preventing, treating, and living with AF. Patients are looking for clear guidance with respect to how best to reduce their risk and burden of AF. Emerging evidence related to diet ${ }^{80}$ caffeine, ${ }^{150}$ yoga, ${ }^{151}$ and acupuncture ${ }^{129}$ represent potentially important steps forward in the incorporation of patient-driven prevention research. Social networking may have a significant role in the prevention and treatment of $\mathrm{AF}$, similar to ongoing efforts in obesity and diabetes management. ${ }^{152}$

The patient perspective is important at both individual and population levels. Clinicians treating AF often consider patients' preferences individually, as reflected in clinical practice guidelines. ${ }^{153}$ Because $\mathrm{AF}$ is a complex and heterogeneous public health problem, it is also appropriate to consider patient preferences at the population level, particularly when considering priorities for research initiatives. ${ }^{154}$ There have been many studies of the patient experience in AF. ${ }^{155}$ There is a robust body of research regarding patient preferences with regard to OAC use, including patient self-monitoring of warfarin therapy. ${ }^{156,157}$ Less is known about patient preferences with regard to NOACs or rhythm control therapies, including catheter ablation. A systematic review of quality of life related to AF therapies demonstrated improvement with rate or rhythm control strategies but offered no further conclusions regarding patient decision-making about these strategies. ${ }^{158}$ Unfortunately, patient preference is seldom coded in systematic observational research regarding AF interventions. ${ }^{159}$ It is noteworthy that recent AF management guidelines systematically address the need to consider patient preferences. ${ }^{82}$

\section{Patient-centered outcomes}

In clinical trials, researchers often use a battery of quality of life indices (ie, SF-36, SF-12, EQOL) coupled with functional performance (ie, 6-minute hall walk test) as surrogate indicators of patient outcomes related to AF therapies. More recently, validated instruments of AF-related quality of life, like the Atrial Fibrillation Effect on QualiTy-of-Life (AFEQT) questionnaire, have been incorporated. ${ }^{160}$ Moving forward, clinical studies should consider the broader impacts of rhythm control therapies on the patient's life experience, including emotional stress, financial costs, and impact on concomitant diagnoses (eg, stroke, HF). It is also important to understand patient access to $\mathrm{AF}$ care at both the individual and population levels.

\section{Optimizing scientific and clinical yield from observational studies and registries}

Large observational studies and multicenter registries play an important role in generating scientific and clinical knowledge at the population level. Registries can provide important insights into clinical epidemiology, disease presentation, risk factors for clinical events and disease progression, treatment utilization and patterns, and patient outcomes. Observational data and registries can include cohorts from large single health-care systems, multicenter studies, administrative claims databases, and national and international disease-based 
registries (often under the leadership of a professional society). Although individual data repositories can be analyzed to answer a variety of clinical questions about the care of $\mathrm{AF}$ patients, these data sources may be even more valuable when merged. For example, analysis of a nationwide cohort of AF patients admitted with HF can help inform long-term outcomes when merged with longitudinal administrative claims data. ${ }^{161}$ As registries evolve to include EHRs and Internet or smartphone-based data capture systems, the possibilities grow. Smartphone diagnosis of PACs in patients enrolled in an existing outpatient cardiology registry could enable identification of risk for AF in "real time," without creation of new study architecture or significant financial investment. Large registries can also provide an efficient platform for large, simple clinical trials. ${ }^{162}$ Using an existing registry to launch a clinical trial can help to identify patients, streamline enrollment, and minimize operational costs.

To create synergy between studies, the data collected must be compatible. Prior professional society statements have helped to define standard data elements in AF, including definitions of AF type. ${ }^{163,164}$ As technologies and clinical knowledge expand, these data definitions and standards will require updates and revision. We recommend that (1) continued dataelement definition and standardization are needed; (2) observational datasets should be linked when possible to maximize their scientific contributions; and (3) registries should be used as a platform to launch large, simple "real world" clinical trials.

Traditional large, high-quality epidemiologic datasets (Framingham Heart Study, the MultiEthnic Study of Atherosclerosis, etc) have required the creation and maintenance of cohorts that are phenotyped in detail at study initiation and then followed at regular intervals. These cohorts have identified key cardiovascular risks, including risks factors for AF. An innovative approach to more efficiently collect observational data is the use of the Internet and/or mobile technologies to create decentralized cohorts followed remotely, using social media to recruit large numbers of participants. Smartphone use is becoming pervasive across all age and socioeconomic groups. With development of less expensive, noninvasive physiologic and behavior sensors, new paradigms for conducting clinical trials, registries, and cohort studies are being developed. Devices available today can track activity, sleep, BP, pulse oximetry, ECG, and weight using smartphones that can seamlessly and reliably capture and transmit data to central servers. The Health eHeart Study (http://www.healtheheartstudy.org) is a study that has developed a large decentralized cardiovascular cohort in an attempt to collect "big data" to better predict, prevent, and treat cardiovascular diseases, including AF.

Use of "eRegistries" like the Health eHeart Study may reduce the costs of large-scale clinical research. Important features of this approach are (1) an online consent process that does not require an in-person visit, (2) an engaging interface, and (3) multiple mechanisms for interventions aimed at participant retention. This program has approval from the University of California San Francisco IRB, and participants are enrolled under their supervision, regardless of where the participant lives or receives health care. In addition to the possibility of performing registry-embedded clinical trials, e-registries also can utilize crowd-sourced research, in which patients or patient advocacy groups become more invested 
in the research. The Health eHeart Study has collaborated with patient advocacy groups such as the American Heart Association and StopAfib to create the Health eHeart Alliance.

The emerging clinical research "fabric" will be woven from registry-driven trials that are conducted in the context of integrated health systems and powered by ubiquitous patient data from EHRs as well as "patient-centered" (or reported) data. This new construct for clinical research has the potential to enable trials to be initiated more quickly and conducted more efficiently, leveraging data already collected as part of routine care and monitoring. New initiatives putting these ideas into practice include the NIH Health Care Systems Collaboratory (http://nihcollaboratory.org) ${ }^{165}$ and PCORnet (http://pcornet.org/); they represent important avenues for future clinical AF research.

Highly developed registries supported by the ACC, AHA, ESC, and other global professional societies should be able to intersect with these resources to create a more efficient, high-throughput system. ${ }^{165}$ The Heart Rhythm Society and its partners are well positioned to make a significant contribution to this process by convening patients, providers, the NIH, and industry to assess the larger clinical trials portfolio, with the aim of applying system resources to the most important consensus priorities in AF.

\section{Key research priorities}

\section{Evaluation of the causative factors involved in prefibrillatory/AF-contributory states}

Given the frequency of AF and its cost to the worldwide health care systems, primary prevention of AF is a critical goal. Despite their importance, effective AF primary prevention strategies remain elusive. To explore, test, and refine AF prevention strategies, careful identification of at-risk patients is paramount. Multiple risk prediction schemes have been derived and validated through cohort and population studies, largely focusing on demographics, comorbidities, and physiologic measurements. ${ }^{53,54}$ Use of genetic approaches to identify individuals at risk for AF is promising but still remains challenging. ${ }^{51}$ An alternative approach is the identification of high-risk electrophysiologic substrates. Several electrophysiologic substrates are known to be prefibrillatory or AF-contributory, and may help to evaluate primary prevention strategies and refine our understanding of the pathogenesis of incident AF.

Obesity, diabetes, hypertension, and sleep apnea are modifiable risk factors that may promote atrial structural remodeling and PAC burden that are strongly associated with AF risk and that warrant attention and remediation for primary and secondary prevention, both separately and in aggregate. As discussed in previous sections, PAC burden is associated with future risk of AF. ${ }^{10,141}$ Increased atrial conduction times and PR prolongation are also associated with increased risk of incident $\mathrm{AF} .{ }^{51} \mathrm{Basic}$ and translational studies that identify and study of the causative factors and mechanisms behind these AF-contributory states are needed. Large observational cohort studies may help to better define the risk and time course of developing AF in these contributory states. EHRs and health information technology may facilitate integration of traditional risk factors, cardiovascular imaging, biomarker data, and other physiologic measures with AF-contributory states to create novel, multimodal AF risk scores. 


\section{Randomized primary prevention of AF in patients at high risk for developing AF}

Despite significant interest and the obvious public health and economic benefits that would follow from the successful prevention of $\mathrm{AF}$, there are no proven interventions for the primary prevention of AF. Most primary prevention studies to date have been post hoc analyses of RCTs conducted for other conditions and end-points. These studies are often limited to AF diagnosis by 12-lead ECG without more in-depth assessment of AF burden and frequently suffer from limited power. Best practice RCTs in patients with multiple risk factors for AF, including AF-contributory states, should be high priorities for government and nongovernmental funding agencies. Candidate interventions (Table 1) might include $\beta$ adrenergic blockers, novel compounds such as $\mathrm{HDAC}^{43}$ and CaMKII ${ }^{17}$ inhibitors, statins or isoform-specific NADPH oxidase inhibitors, ${ }^{27}$ and autonomic modulation.

As suggested above, systematic longitudinal studies are also needed to evaluate the value of aggressively treating AF-related risk factors, including obesity, diabetes, hypertension, and sleep apnea, for the prevention of incident AF. Early identification and treatment of these conditions may help to limit atrial remodeling and the propensity to develop AF. Future clinical trials of primary prevention therapies will need to focus on patients at sufficient risk but should not be restrictive. Ideally, these trials would be large "simple" randomized trials, embedded in a professional society registry, and focused on effectiveness.

\section{Advancing secondary AF prevention}

Although primary prevention of AF cannot be overemphasized, the distinction between primary and secondary prevention is somewhat arbitrary. Development of AF and underlying disease progression represents a continuum. ${ }^{16}$ Therapeutic attempts to interrupt this continuum are important both for persons at risk for $\mathrm{AF}$ and those with recurrent AF. To improve the efficacy of secondary AF prevention, more focused efforts to address the modifiable risk AF factors (hypertension, obesity, diabetes, sleep disordered breathing) are needed, in addition to targeting the triggers and the anatomic/functional substrate for AF.

\section{Integrating and coordinating the activity of HRS members and global collaborators}

For the Heart Rhythm Society to have an enduring impact on scientific research focused on answering the most urgent questions concerning AF and stroke, it will be important to set up a structure that effectively harnesses the time and talents of HRS members and global partners. During the research forum, several possible strategies were discussed.

The first strategy was the development of a Heart Rhythm Trials network, patterned after the NIH-funded Cardiac Surgery or Heart Failure Trials networks. For such a proposal to be feasible, participants would need to prepare a multisite application with detailed plans for a series of compelling and feasible studies that the network would undertake, with sufficient evidence to support both the feasibility and the scientific and clinical benefit that would justify the creation of such a network. NIH resources are currently quite constrained, and significant costs are associated with developing the infrastructure needed to support these clinical trial networks. 
An alternative strategy would be one in which the HRS develops a mechanism to bring researchers together around specific research projects focused on AF and stroke. Once a compelling question is identified, researchers from various institutions can join together to craft and conduct the clinical trial. The Canadian Heart Rhythm Society has been very successful in utilizing such an approach throughout Canada to collaborate in an informal clinical trials network. Unlike a federally funded clinical trial network grant, this concept avoids the considerable costs of creating a large infrastructure to support a family of trials.

A third alternative to advance AF clinical science would be the development of a voluntary AF ablation registry. An initial attempt to accomplish this goal was undertaken by the Safety of Atrial Fibrillation Ablation Registry Initiative (SAFARI) working group. Although considerable progress was made, funding was never secured to launch this AF ablation registry. With increased awareness of the value of clinical registries, another effort to developing a voluntary AF ablation registry could be successful. This Research Forum recommends that the Heart Rhythm Society should develop a working group to focus on this issue.

\section{Consensus top priorities for AF research}

Based on reviews of existing epidemiologic trends, basic science, clinical outcomes, and unmet needs in clinical practice, the research committee and key stakeholders articulated top priorities for AF research that will advance progress toward the primary and secondary prevention of AF. Figure 4 summarizes our current research priorities; these can be divided into several key themes, including improving our understanding of the role of modifiable risk factors on AF pathophysiology and progression, improving risk stratification, and better understanding of current clinical outcomes. The focus on innovation in clinical research methods highlights the importance of changing the way we conduct clinical investigation. Improved clinical trial methods are needed in order to provide more relevant answers to clinical questions and in a more efficient and timely manner.

\section{Top basic science/translational research priorities}

1. Elucidate the mechanisms underlying ectopy originating from the PVs and other sources in pAF patients, and determine why this ectopy predominantly results in $\mathrm{AF}$ in older individuals.

2. Identify the genes, signaling pathways, and mechanisms by which genetic loci associated with AF risk impact atrial physiology, and evaluate the interaction of these pathways with modifiable risk factors.

3. Determine the stage(s) at which $\mathrm{AF}$ risk factor reduction (weight loss, BP management, sleep apnea, etc) can reverse atrial structural remodeling and/or conduction heterogeneity, and help to prevent (or slow the progression of) AF.

4. Develop new preventive treatments focused on key AF mechanisms (atrial ectopy, oxidant stress, proteostasis, fibrosis, etc) to enhance safety and efficacy. 


\section{Top clinical research priorities}

1. Develop and validate an AF risk score using developing and contemporary technologies, including genetic markers, electrocardiographic variables, biomarker data, imaging data, autonomic data, and AF-contributory states.

2. Perform RCTs of primary prevention strategies of AF in patients with high AF risk scores.

3. Establish new AF registries or utilize existing AF registries to launch large, simple, "real world" clinical trials."

4. Use or create observational cohort studies to better define the risk and time course of developing AF in known AF-contributory states such as frequent PACs, prolonged atrial conduction time, and atrial flutter, and to discover new ones.

5. Develop novel social science approaches to enhance patient participation, engagement, and compliance in long-term preventive lifestyle modification studies.

6. Create an $\mathrm{AF}$ trials network to facilitate the conception,design, initiation, execution, and completion of innovative clinical trials designed address key clinical priorities,as defined by providers, patients, and payers.

\section{Priorities that continue from the 2008 AF Prevention Report ${ }^{1}$}

7. Continue to develop large animal models with spontaneous initiation of AF.

8. Continue to improve and validate noninvasive methods to image AF, to quantify LA fibrosis, and to image the brain (for AF/stroke risk stratification).

\section{Conclusion}

Despite continued improvements in the treatment of AF, effective methods for preventing AF remain elusive. Important targets for preventive therapy include both the processes underlying the development of triggers for $\mathrm{AF}$ and the substrate susceptible to AF. We need to better evaluate the impact of early treatment of known AF risk factors. Cellular and physiologic targets that are important areas of ongoing and future research include atrial ectopy, calcium handling, atrial fibrosis, atrial myocyte proteostasis, and oxidant stress. Similarly, research is needed in order to better understand how risk factor modification impacts future risk of AF, including treatment of hypertension, diabetes, obesity, HF, and sleep disordered breathing. Important clinical priorities include better methods of noninvasive atrial imaging and methods of atrial trigger and substrate modification, including advances in catheter ablation and novel drug therapies. Clinical research priorities are accompanied by important and needed changes in methodology. Incorporation of patient-centered outcomes, utilization of existing and emerging registries for the development and execution of large, real-world, and simple clinical trials, and the creation of an AF clinical trials network are among the important priorities. The growing prevalence of AF remains a daunting public health problem. The mindset of health care providers focused on primary AF prevention will need to change from the current focus on procedures on individual patients to a broader focus on the identification and treatment of risk factor 
reduction in the population of the at-risk patients. Cooperation and collaboration between professional societies, practicing clinicians, clinical investigators, basic scientists, patient advocacy groups, funding agencies, government, industry, and health care systems will be paramount if we are to stem the tide of $\mathrm{AF}$ and reduce its associated morbidity and mortality.

\section{Supplementary Material}

Refer to Web version on PubMed Central for supplementary material.

\section{Acknowledgments}

We gratefully acknowledge the outstanding organizational and logistic support from Lisa Olson, $\mathrm{PhD}$, Stephanie Demian, and Lena Timmons. Funding for the Research Forum was provided in part by a grant from Elsevier.

\section{References}

1. Benjamin EJ, Chen PS, Bild DE, et al. Prevention of atrial fibrillation: report from a national heart, lung, and blood institute workshop. Circulation. 2009; 119:606-618. [PubMed: 19188521]

2. Chugh SS, Havmoeller R, Narayanan K, et al. Worldwide epidemiology of atrial fibrillation: a global burden of disease 2010 study. Circulation. 2014; 129:837-847. [PubMed: 24345399]

3. Lloyd-Jones DM, Wang TJ, Leip EP, Larson MG, Levy D, Vasan RS, D'Agostino RB, Massaro JM, Beiser A, Wolf PA, Benjamin EJ. Lifetime risk for development of atrial fibrillation: the Framingham Study. Circulation. 2004; 110:1042-1046. [PubMed: 15313941]

4. Committee on Comparative Effectiveness Research Prioritization IoM. Initial National Priorities for Comparative Effectiveness Research. Washington, DC: The National Academies Press; 2009.

5. Go AS, Mozaffarian D, Roger VL, et al. Heart disease and stroke statistics-2014 update: a report from the American Heart Association. Circulation. 2014; 129:e28-e292. [PubMed: 24352519]

6. Sussman M, Menzin J, Lin I, Kwong WJ, Munsell M, Friedman M, Selim M. Impact of atrial fibrillation on stroke-related healthcare costs. J Am Heart Assoc. 2013; 2:e000479. [PubMed: 24275631]

7. Tricoci P, Allen JM, Kramer JM, Califf RM, Smith SC Jr. Scientific evidence underlying the ACC/AHA clinical practice guidelines. JAMA. 2009; 301:831-841. [PubMed: 19244190]

8. Califf RM, Zarin DA, Kramer JM, Sherman RE, Aberle LH, Tasneem A. Characteristics of clinical trials registered in ClinicalTrials.gov, 2007-2010. JAMA 2012;307:1838-1847.

9. Ross JS, Tse T, Zarin DA, Xu H, Zhou L, Krumholz HM. Publication of NIH funded trials registered in ClinicalTrials.gov: cross sectional analysis. BMJ 2012;344:d7292.

10. Dewland TA, Vittinghoff E, Mandyam MC, Heckbert SR, Siscovick DS, Stein PK, Psaty BM, Sotoodehnia N, Gottdiener JS, Marcus GM. Atrial ectopy as a predictor of incident atrial fibrillation: a cohort study. Ann Intern Med. 2013; 159:721-728. [PubMed: 24297188]

11. Conen D, Adam M, Roche F, et al. Premature atrial contractions in the general population: frequency and risk factors. Circulation. 2012; 126:2302-2308. [PubMed: 23048073]

12. Preliminary report: effect of encainide and flecainide on mortality in a randomized trial of arrhythmia suppression after myocardial infarction. The Cardiac Arrhythmia Suppression Trial (CAST) Investigators. N Engl J Med. 1989; 321:406-412. [PubMed: 2473403]

13. Frost L, Christiansen EH, Molgaard H, Jacobsen CJ, Allermand H, Thomsen PE. Premature atrial beat eliciting atrial fibrillation after coronary artery bypass grafting. J Electrocardiol. 1995; 28:297-305. [PubMed: 8551172]

14. Wakili R, Voigt N, Kaab S, Dobrev D, Nattel S. Recent advances in the molecular pathophysiology of atrial fibrillation. J Clin Invest. 2011; 121:2955-2968. [PubMed: 21804195] 
15. Haissaguerre M, Jais P, Shah DC, Takahashi A, Hocini M, Quiniou G, Garrigue S, Le Mouroux A, Le Metayer P, Clementy J. Spontaneous initiation of atrial fibrillation by ectopic beats originating in the pulmonary veins. N Eng J Med. 1998; 339:659-666.

16. Heijman J, Voigt N, Nattel S, Dobrev D. Cellular and molecular electro-physiology of atrial fibrillation initiation, maintenance, and progression. Circ Res. 2014; 114:1483-1499. [PubMed: 24763466]

17. Heijman J, Voigt N, Wehrens XH, Dobrev D. Calcium dysregulation in atrial fibrillation: the role of CaMKII. Front Pharmacol. 2014; 5:30. [PubMed: 24624086]

18. Voigt N, Heijman J, Wang Q, Chiang DY, Li N, Karck M, Wehrens XH, Nattel S, Dobrev D. Cellular and molecular mechanisms of atrial arrhythmogenesis in patients with paroxysmal atrial fibrillation. Circulation. 2014; 129:145-156. [PubMed: 24249718]

19. Beavers DL, Wang W, Ather S, et al. Mutation E169K in junctophilin-2 causes atrial fibrillation due to impaired RyR2 stabilization. J Am Coll Cardiol. 2013; 62:2010-2019. [PubMed: 23973696]

20. Dobrev D, Carlsson L, Nattel S. Novel molecular targets for atrial fibrillation therapy. Nat Rev Drug Discov. 2012; 11:275-291. [PubMed: 22460122]

21. Tagarakis GI, Aidonidis I, Daskalopoulou SS, Simopoulos V, Liouras V, Daskalopoulos ME, Parisis C, Papageorgiou K, Skoularingis I, Triposkiadis F, Molyvdas PA, Tsilimingas NB. Effect of ranolazine in preventing postoperative atrial fibrillation in patients undergoing coronary revascularization surgery. Curr Vasc Pharmacol. 2013; 11:988-991. [PubMed: 23140547]

22. Wagner S, Ruff HM, Weber SL, Bellmann S, Sowa T, Schulte T, Anderson ME, Grandi E, Bers DM, Backs J, Belardinelli L, Maier LS. Reactive oxygen species-activated Ca/calmodulin kinase IIdelta is required for late $\mathrm{I}(\mathrm{Na})$ augmentation leading to cellular $\mathrm{Na}$ and Ca overload. Circ Res. 2011; 108:555-565. [PubMed: 21252154]

23. Aldakkak M, Camara AK, Heisner JS, Yang M, Stowe DF. Ranolazine reduces Ca2+ overload and oxidative stress and improves mitochondrial integrity to protect against ischemia reperfusion injury in isolated hearts. Pharmacol Res. 2011; 64:381-392. [PubMed: 21741479]

24. Purohit A, Rokita AG, Guan X, et al. Oxidized Ca(2+)/calmodulin-dependent protein kinase II triggers atrial fibrillation. Circulation. 2013; 128:1748-1757. [PubMed: 24030498]

25. Singh MV, Kapoun A, Higgins L, et al. Ca2+/calmodulin-dependent kinase II triggers cell membrane injury by inducing complement factor B gene expression in the mouse heart. J Clin Invest. 2009; 119:986-996. [PubMed: 19273909]

26. He BJ, Joiner ML, Singh MV, et al. Oxidation of CaMKII determines the cardiotoxic effects of aldosterone. Nat Med. 2011; 17:1610-1618. [PubMed: 22081025]

27. Pinho-Gomes AC, Reilly S, Brandes RP, Casadei B. Targeting inflammation and oxidative stress in atrial fibrillation: role of 3-hydroxy-3-methylglutaryl-coenzyme a reductase inhibition with statins. Antioxid Redox Signal. 2014; 20:1268-1285. [PubMed: 23924190]

28. Prosser BL, Ward CW, Lederer WJ. X-ROS signaling: rapid mechano-chemo transduction in heart. Science. 2011; 333:1440-1445. [PubMed: 21903813]

29. Watanabe H, Chopra N, Laver D, Hwang HS, Davies SS, Roach DE, Duff HJ, Roden DM, Wilde AA, Knollmann BC. Flecainide prevents catecholaminergic polymorphic ventricular tachycardia in mice and humans. Nat Med. 2009; 15:380-383. [PubMed: 19330009]

30. Zhou Q, Xiao J, Jiang D, et al. Carvedilol and its new analogs suppress arrhythmogenic store overload-induced Ca2+ release. Nat Med. 2011; 17:1003-1009. [PubMed: 21743453]

31. Currie S, Elliott EB, Smith GL, Loughrey CM. Two candidates at the heart of dysfunction: the ryanodine receptor and calcium/calmodulin protein kinase II as potential targets for therapeutic intervention-An in vivo perspective. Pharmacol Ther. 2011; 131:204-220. [PubMed: 21414358]

32. Igarashi T, Finet JE, Takeuchi A, Fujino Y, Strom M, Greener ID, Rosenbaum DS, Donahue JK. Connexin gene transfer preserves conduction velocity and prevents atrial fibrillation. Circulation. 2012; 125:216-225. [PubMed: 22158756]

33. Ravens U, Poulet C, Wettwer E, Knaut M. Atrial selectivity of antiarrhythmic drugs. J Physiol. 2013; 591:4087-4097. [PubMed: 23732646]

34. Tuteja D, Xu D, Timofeyev V, Lu L, Sharma D, Zhang Z, Xu Y, Nie L, Vazquez AE, Young JN, Glatter KA, Chiamvimonvat N. Differential expression of small-conductance Ca2+-activated K+ 
channels SK1, SK2, and SK3 in mouse atrial and ventricular myocytes. Am J Physiol Heart Circ Physiol. 2005; 289:H2714-H2723. [PubMed: 16055520]

35. Ellinor PT, Lunetta KL, Glazer NL, et al. Common variants in KCNN3 are associated with lone atrial fibrillation. Nat Genet. 2010; 42:240-244. [PubMed: 20173747]

36. Ozgen N, Dun W, Sosunov EA, Anyukhovsky EP, Hirose M, Duffy HS, Boyden PA, Rosen MR. Early electrical remodeling in rabbit pulmonary vein results from trafficking of intracellular SK2 channels to membrane sites. Cardiovasc Res. 2007; 75:758-769. [PubMed: 17588552]

37. Qi XY, Diness JG, Brundel B, Zhou XB, Naud P, Wu CT, Huang H, Harada M, Aflaki M, Dobrev D, Grunnet M, Nattel S. Role of small conductance calcium-activated potassium channels in atrial electrophysiology and fibrillation in the dog. Circulation. 2014; 129:430-440. [PubMed: 24190961]

38. Ogawa T, de Bold AJ. The heart as an endocrine organ. Endocr Connect. 2014; 3:R31-R44. [PubMed: 24562677]

39. Goudis CA, Kallergis EM, Vardas PE. Extracellular matrix alterations in the atria: insights into the mechanisms and perpetuation of atrial fibrillation. Europace. 2012; 14:623-630. [PubMed: 22237583]

40. Yue L, Xie J, Nattel S. Molecular determinants of cardiac fibroblast electrical function and therapeutic implications for atrial fibrillation. Cardiovasc Res. 2011; 89:744-753. [PubMed: 20962103]

41. Burstein B, Nattel S. Atrial structural remodeling as an antiarrhythmic target. J Cardiovasc Pharmacol. 2008; 52:4-10. [PubMed: 18594481]

42. Saez I, Vilchez D. The mechanistic links between proteasome activity, aging and age-related diseases. Curr Genomics. 2014; 15:38-51. [PubMed: 24653662]

43. Zhang D, Wu CT, Qi X, et al. Activation of histone deacetylase-6 induces contractile dysfunction through derailment of alpha-tubulin proteostasis in experimental and human atrial fibrillation. Circulation. 2014; 129:346-358. [PubMed: 24146251]

44. Powers ET, Balch WE. Diversity in the origins of proteostasis networks-a driver for protein function in evolution. Nat Rev Mol Cell Biol. 2013; 14:237-248.

45. Meijering RA, Zhang D, Hoogstra-Berends F, Henning RH, Brundel BJ. Loss of proteostatic control as a substrate for atrial fibrillation: a novel target for upstream therapy by heat shock proteins. Front Physiol. 2012; 3:36. [PubMed: 22375124]

46. Hoogstra-Berends F, Meijering RAM, Zhang D, Heeres A, Loen L, Seerden JP, Kuipers I, Kampinga HH, Henning RH, Brundel BJJM. Heat shock protein-inducing compounds as therapeutics to restore proteostasis in atrial fibrillation. Trends Cardiovasc Med. 2012; 22:62-68. [PubMed: 22863365]

47. Xiao J, Zhang H, Liang D, Liu Y, Liu Y, Zhao H, Li J, Peng L, Taxol, Chen YH. a microtubule stabilizer, prevents atrial fibrillation in in vitro atrial fibrillation models using rabbit hearts. Med Sci Monit. 2010; 16:BR353-BR360. [PubMed: 20980952]

48. Imazio M, Brucato A, Ferrazzi P, et al. Colchicine for Prevention of Postpericardiotomy Syndrome and Postoperative Atrial Fibrillation: the COPPS-2 randomized clinical trial. JAMA. 2014; 312:1016-1023. [PubMed: 25172965]

49. Deftereos S, Giannopoulos G, Efremidis M, et al. Colchicine for prevention of atrial fibrillation recurrence after pulmonary vein isolation: mid-term efficacy and effect on quality of life. Heart Rhythm. 2014; 11:620-628. [PubMed: 24508207]

50. Imazio M, Brucato A, Ferrazzi P, et al. Colchicine reduces postoperative atrial fibrillation: results of the Colchicine for the Prevention of the Postpericardiotomy Syndrome (COPPS) atrial fibrillation substudy. Circulation. 2011; 124:2290-2295. [PubMed: 22090167]

51. Tucker NR, Ellinor PT. Emerging directions in the genetics of atrial fibrillation. Circ Res. 2014; 114:1469-1482. [PubMed: 24763465]

52. Lubitz SA, Yin X, Fontes JD, et al. Association between familial atrial fibrillation and risk of newonset atrial fibrillation. JAMA. 2010; 304:2263-2269. [PubMed: 21076174]

53. Schnabel RB, Aspelund T, Li G, et al. Validation of an atrial fibrillation risk algorithm in whites and African Americans. Arch Intern Med. 2010; 170:1909-1917. [PubMed: 21098350] 
54. Chamberlain AM, Agarwal SK, Folsom AR, Soliman EZ, Chambless LE, Crow R, Ambrose M, Alonso A. A clinical risk score for atrial fibrillation in a biracial prospective cohort (from the Atherosclerosis Risk in Communities [ARIC] study). Am J Cardiol. 2011; 107:85-91. [PubMed: 21146692]

55. Alonso A, Krijthe BP, Aspelund T, et al. Simple risk model predicts incidence of atrial fibrillation in a racially and geographically diverse population: the CHARGE-AF Consortium. J Am Heart Assoc. 2013; 2:e000102. [PubMed: 23537808]

56. Rienstra M, McManus DD, Benjamin EJ. Novel risk factors for atrial fibrillation: useful for risk prediction and clinical decision making? Circulation. 2012; 125:e941-e946. [PubMed: 22615425]

57. Everett BM, Cook NR, Conen D, Chasman DI, Ridker PM, Albert CM. Novel genetic markers improve measures of atrial fibrillation risk prediction. Eur Heart J. 2013; 34:2243-2251. [PubMed: 23444395]

58. Schnabel RB, Larson MG, Yamamoto JF, Kathiresan S, Rong J, Levy D, Keaney JF Jr, Wang TJ, Vasan RS, Benjamin EJ. Relation of multiple inflammatory biomarkers to incident atrial fibrillation. Am J Cardiol. 2009; 104:92-96. [PubMed: 19576326]

59. Schnabel RB, Larson MG, Yamamoto JF, et al. Relations of biomarkers of distinct pathophysiological pathways and atrial fibrillation incidence in the community. Circulation. 2010; 121:200-207. [PubMed: 20048208]

60. Hlatky MA, Greenland P, Arnett DK, et al. Criteria for evaluation of novel markers of cardiovascular risk: a scientific statement from the American Heart Association. Circulation. 2009; 119:2408-2416. [PubMed: 19364974]

61. Huxley RR, Lopez FL, Folsom AR, Agarwal SK, Loehr LR, Soliman EZ, Maclehose R, Konety S, Alonso A. Absolute and attributable risks of atrial fibrillation in relation to optimal and borderline risk factors: the Atherosclerosis Risk in Communities (ARIC) Study. Circulation. 2011; 123:15011508. [PubMed: 21444879]

62. Yin X, Zhao Y, Xi Y, Cheng N, Xia Y, Zhang S, Dong Y, Chang D, Cheng J, Yang Y, Gao L. The early stage of the atrial electroanatomic remodeling as substrates for atrial fibrillation in hypertensive patients. J Am Heart Assoc. 2014; 3

63. Okin PM, Wachtell K, Devereux RB, Harris KE, Jern S, Kjeldsen SE, Julius S, Lindholm LH, Nieminen MS, Edelman JM, Hille DA, Dahlof B. Regression of electrocardiographic left ventricular hypertrophy and decreased incidence of new-onset atrial fibrillation in patients with hypertension. JAMA. 2006; 296:1242-1248. [PubMed: 16968848]

64. Parati G, Omboni S, Compare A, et al. Blood pressure control and treatment adherence in hypertensive patients with metabolic syndrome: protocol of a randomized controlled study based on home blood pressure telemonitoring vs. conventional management and assessment of psychological determinants of adherence (TELEBPMET Study). Trials. 2013; 14:22. [PubMed: 23343138]

65. Rudolph V, Andrie RP, Rudolph TK, et al. Myeloperoxidase acts as a profibrotic mediator of atrial fibrillation. Nat Med. 2010; 4:470-474. [PubMed: 20305660]

66. Healey JS, Baranchuk A, Crystal E, Morillo CA, Garfinkle M, Yusuf S, Connolly SJ. Prevention of atrial fibrillation with angiotensin-converting enzyme inhibitors and angiotensin receptor blockers: a meta-analysis. J Am Coll Cardiol. 2005; 45:1832-1839. [PubMed: 15936615]

67. Wachtell K, Lehto M, Gerdts E, Olsen MH, Hornestam B, Dahlof B, Ibsen H, Julius S, Kjeldsen SE, Lindholm LH, Nieminen MS, Devereux RB. Angiotensin II receptor blockade reduces newonset atrial fibrillation and subsequent stroke compared to atenolol: the Losartan Intervention For End Point Reduction in Hypertension (LIFE) study. J Am Coll Cardiol. 2005; 45:712-719. [PubMed: 15734615]

68. Marott SC, Nielsen SF, Benn M, Nordestgaard BG. Antihypertensive treatment and risk of atrial fibrillation: a nationwide study. Eur Heart J. 2014; 35:1205-1214. [PubMed: 24347316]

69. Madrid AH, Bueno MG, Rebollo JM, Marin I, Pena G, Bernal E, Rodriguez A, Cano L, Cano JM, Cabeza P, Moro C. Use of irbesartan to maintain sinus rhythm in patients with long-lasting persistent atrial fibrillation: a prospective and randomized study. Circulation. 2002; 106:331-336. [PubMed: 12119249] 
70. Disertori M, Latini R, Barlera S, Franzosi MG, Staszewsky L, Maggioni AP, Lucci D, Di Pasquale G, Tognoni G. GISSI-AF Investigators. Valsartan for prevention of recurrent atrial fibrillation. N Engl J Med. 2009; 360:1606-1617. [PubMed: 19369667]

71. Gillis AM. Angiotensin-receptor blockers for prevention of atrial fibrillation-a matter of timing or target? N Engl J Med. 2009; 360:1669-1671. [PubMed: 19369674]

72. Mayyas F, Alzoubi KH, Van Wagoner DR. Impact of aldosterone antagonists on the substrate for atrial fibrillation: aldosterone promotes oxidative stress and atrial structural/electrical remodeling. Int J Cardiol. 2013; 168:5135-5142. [PubMed: 23993726]

73. Calhoun DA, Jones D, Textor S, et al. Resistant hypertension: diagnosis, evaluation, and treatment: a scientific statement from the American Heart Association Professional Education Committee of the Council for High Blood Pressure Research. Circulation. 2008; 117:e510-e526. [PubMed: 18574054]

74. Bhatt DL, Kandzari DE, O'Neill WW, et al. A controlled trial of renal denervation for resistant hypertension. N Engl J Med. 2014; 370:1393-1401. [PubMed: 24678939]

75. Pokushalov E, Romanov A, Katritsis DG, Artyomenko S, Bayramova S, Losik D, Baranova V, Karaskov A, Steinberg JS. Renal denervation for improving outcomes of catheter ablation in 1285 patients with atrial fibrillation and hypertension: early experience. Heart Rhythm. 2014; 11:11311286. [PubMed: 24691452]

76. Frost L, Hune LJ, Vestergaard P. Overweight and obesity as risk factors for atrial fibrillation or flutter: the Danish Diet, Cancer, and Health Study. Am J Med. 2005; 118:489-495. [PubMed: 15866251]

77. Zacharias A, Schwann TA, Riordan CJ, Durham SJ, Shah AS, Habib RH. Obesity and risk of newonset atrial fibrillation after cardiac surgery. Circulation. 2005; 112:3247-3255. [PubMed: 16286585]

78. Kwiatkowski P, Sai-Sudhakar C, Philips A, Parthasarathy S, Sun B. Development of a novel large animal model of ischemic heart failure using autologous platelet aggregates. Int J Artif Organs. 2010; 33:63-71. [PubMed: 20306432]

79. Abed HS, Samuel CS, Lau DH, et al. Obesity results in progressive atrial structural and electrical remodeling: implications for atrial fibrillation. Heart Rhythm. 2013; 10:90-100. [PubMed: 23063864]

80. Abed HS, Wittert GA, Leong DP, et al. Effect of weight reduction and cardiometabolic risk factor management on symptom burden and severity in patients with atrial fibrillation: a randomized clinical trial. JAMA. 2013; 310:2050-2060. [PubMed: 24240932]

81. Chow E, Bernjak A, Williams S, Fawdry RA, Hibbert S, Freeman J, Sheridan PJ, Heller SR. Risk of cardiac arrhythmias during hypoglycemia in patients with type 2 diabetes and cardiovascular risk. Diabetes. 2014; 63:1738-1747. [PubMed: 24757202]

82. January CT, Wann LS, Alpert JS, et al. 2014 AHA/ACC/HRS Guideline for the Management of Patients With Atrial Fibrillation: A Report of the American College of Cardiology/American Heart Association Task Force on Practice Guidelines and the Heart Rhythm Society. J Am Coll Cardiol. 2014; 64:e1-e76. [PubMed: 24685669]

83. Trulock KM, Narayan SM, Piccini JP. Rhythm control in heart failure patients with atrial fibrillation: contemporary challenges including the role of ablation. J Am Coll Cardiol. 2014; 64:710-721. [PubMed: 25125304]

84. Khatib R, Joseph P, Briel M, Yusuf S, Healey J. Blockade of the renin-angiotensin-aldosterone system (RAAS) for primary prevention of non-valvular atrial fibrillation: a systematic review and meta analysis of randomized controlled trials. Int J Cardiol. 2013; 165:17-24. [PubMed: 22421406]

85. Investigators ES, Swedberg K, Zannad F, McMurray JJ, Krum H, van Veldhuisen DJ, Shi H, Vincent J, Pitt B. Eplerenone and atrial fibrillation in mild systolic heart failure: results from the EMPHASIS-HF (Eplerenone in Mild Patients Hospitalization And SurvIval Study in Heart Failure) study. J Am Coll Cardiol. 2012; 59:1598-1603. [PubMed: 22538330]

86. Aleong RG, Sauer WH, Sauer WH, Murphy GA, Port JD, Anand IS, Fiuzat M, O'Connor CM, Abraham WT, Liggett SB, Bristow MR. Prevention of atrial fibrillation by bucindolol is dependent 
on the beta(1)389 Arg/Gly adrenergic receptor polymorphism. JACC Heart Fail. 2013; 1:338-344. [PubMed: 24159564]

87. Mehra R, Stone KL, Varosy PD, Hoffman AR, Marcus GM, Blackwell T, Ibrahim OA, Salem R, Redline S. Nocturnal Arrhythmias across a spectrum of obstructive and central sleep-disordered breathing in older men: outcomes of sleep disorders in older men (MrOS sleep) study. Arch Intern Med. 2009; 169:1147-1155. [PubMed: 19546416]

88. Neilan TG, Farhad H, Dodson JA, et al. Effect of sleep apnea and continuous positive airway pressure on cardiac structure and recurrence of atrial fibrillation. J Am Heart Assoc. 2013; 2:e000421. [PubMed: 24275628]

89. Fein AS, Shvilkin A, Shah D, Haffajee CI, Das S, Kumar K, Kramer DB, Zimetbaum PJ, Buxton AE, Josephson ME, Anter E. Treatment of obstructive sleep apnea reduces the risk of atrial fibrillation recurrence following catheter ablation. J Am Coll Cardiol. 2013; 62:300-305. [PubMed: 23623910]

90. Kanagala R, Murali NS, Friedman PA, Ammash NM, Gersh BJ, Ballman KV, Shamsuzzaman AS, Somers VK. Obstructive sleep apnea and the recurrence of atrial fibrillation. Circulation. 2003; 107:2589-2594. [PubMed: 12743002]

91. Patel D, Mohanty P, Di Biase L, et al. Safety and efficacy of pulmonary vein antral isolation in patients with obstructive sleep apnea: the impact of continuous positive airway pressure. Circ Arrhythm Electrophysiol. 2010; 3:445-451. [PubMed: 20689107]

92. Ramanathan C, Ghanem RN, Jia P, Ryu K, Rudy Y. Noninvasive electrocardiographic imaging for cardiac electrophysiology and arrhythmia. Nat Med. 2004; 10:422-428. [PubMed: 15034569]

93. Oakes RS, Badger TJ, Kholmovski EG, et al. Detection and quantification of left atrial structural remodeling with delayed-enhancement magnetic resonance imaging in patients with atrial fibrillation. Circulation. 2009; 119:1758-1767. [PubMed: 19307477]

94. Marrouche NF, Wilber D, Hindricks G, et al. Association of atrial tissue fibrosis identified by delayed enhancement MRI and atrial fibrillation catheter ablation: the DECAAF study. JAMA. 2014; 311:498-506. [PubMed: 24496537]

95. Malcolme-Lawes LC, Juli C, Karim R, et al. Automated analysis of atrial late gadolinium enhancement imaging that correlates with endocardial voltage and clinical outcomes: a 2-center study. Heart Rhythm. 2013; 10:1184-1191. [PubMed: 23685170]

96. Narayan SM, Krummen DE, Shivkumar K, Clopton P, Rappel WJ, Miller JM. Treatment of atrial fibrillation by the ablation of localized sources: CONFIRM (Conventional Ablation for Atrial Fibrillation With or Without Focal Impulse and Rotor Modulation) trial. J Am Coll Cardiol. 2012; 60:628-636. [PubMed: 22818076]

97. Jarman JW, Wong T, Kojodjojo P, Spohr H, Davies JE, Roughton M, Francis DP, Kanagaratnam P, Markides V, Davies DW, Peters NS. Spatiotemporal behavior of high dominant frequency during paroxysmal and persistent atrial fibrillation in the human left atrium. Circ Arrhythm Electrophysiol. 2012; 5:650-658. [PubMed: 22722660]

98. Schilling RJ, Peters NS, Davies DW. Feasibility of a noncontact catheter for endocardial mapping of human ventricular tachycardia. Circulation. 1999; 99:2543-2552. [PubMed: 10330386]

99. Shah AJ, Hocini M, Xhaet O, et al. Validation of novel 3-dimensional electrocardiographic mapping of atrial tachycardias by invasive mapping and ablation: a multicenter study. J Am Coll Cardiol. 2013; 62:889-897. [PubMed: 23727090]

100. Sanders P, Hocini M, Jais P, et al. Characterization of focal atrial tachycardia using high-density mapping. J Am Coll Cardiol. 2005; 46:2088-2099. [PubMed: 16325047]

101. Gillis AM, Krahn AD, Skanes AC, Nattel S. Management of atrial fibrillation in the year 2033: new concepts, tools, and applications leading to personalized medicine. Can J Cardiol. 2013; 29:1141-1146. [PubMed: 23988338]

102. Kowalski M, Grimes MM, Perez FJ, Kenigsberg DN, Koneru J, Kasirajan V, Wood MA, Ellenbogen KA. Histopathologic characterization of chronic radio-frequency ablation lesions for pulmonary vein isolation. J Am Coll Cardiol. 2012; 59:930-938. [PubMed: 22381429]

103. Ranjan R, Kato R, Zviman MM, Dickfeld TM, Roguin A, Berger RD, Tomaselli GF, Halperin HR. Gaps in the ablation line as a potential cause of recovery from electrical isolation and their visualization using MRI. Circ Arrhythm Electrophysiol. 2011; 4:279-286. [PubMed: 21493875] 
104. McLellan AJ, Kumar S, Smith C, Morton JB, Kalman JM, Kistler PM. The role of adenosine following pulmonary vein isolation in patients undergoing catheter ablation for atrial fibrillation: a systematic review. J Cardiovasc Electrophysiol. 2013; 24:742-751. [PubMed: 23489944]

105. Dixit S, Marchlinski FE, Lin D, et al. Randomized ablation strategies for the treatment of persistent atrial fibrillation: RASTA study. Circ Arrhythm Electrophysiol. 2012; 5:287-294. [PubMed: 22139886]

106. Di Biase L, Burkhardt JD, Mohanty P, et al. Left atrial appendage: an underrecognized trigger site of atrial fibrillation. Circulation. 2010; 122:109-118. [PubMed: 20606120]

107. Stiles MK, John B, Wong CX, Kuklik P, Brooks AG, Lau DH, Dimitri H, Roberts-Thomson KC, Wilson L, De Sciscio P, Young GD, Sanders P. Paroxysmal lone atrial fibrillation is associated with an abnormal atrial substrate: characterizing the "second factor". J Am Coll Cardiol. 2009; 53:1182-1191. [PubMed: 19341858]

108. Pandit SV, Berenfeld O, Anumonwo JM, Zaritski RM, Kneller J, Nattel S, Jalife J. Ionic determinants of functional reentry in a 2-D model of human atrial cells during simulated chronic atrial fibrillation. Biophys J. 2005; 88:3806-3821. [PubMed: 15792974]

109. de Groot NM, Houben RP, Smeets JL, Boersma E, Schotten U, Schalij MJ, Crijns H, Allessie MA. Electropathological substrate of longstanding persistent atrial fibrillation in patients with structural heart disease. epicardial break-through. Circulation. 2010; 122:1674-1682. [PubMed: 20937979]

110. Scherlag BJ, Nakagawa H, Jackman WM, Yamanashi WS, Patterson E, Po S, Lazzara R. Electrical stimulation to identify neural elements on the heart: their role in atrial fibrillation. $\mathrm{J}$ IntervCard Electrophysiol. 2005; 13(Suppl 1):37-42.

111. Choi EK, Shen MJ, Han S, Kim D, Hwang S, Sayfo S, Piccirillo G, Frick K, Fishbein MC, Hwang C, Lin SF, Chen PS. Intrinsic cardiac nerve activity and paroxysmal atrial tachyarrhythmia in ambulatory dogs. Circulation. 2010; 121:2615-2623. [PubMed: 20529998]

112. Katritsis DG, Pokushalov E, Romanov A, Giazitzoglou E, Siontis GC, Po SS, Camm AJ, Ioannidis JP. Autonomic denervation added to pulmonary vein isolation for paroxysmal atrial fibrillation: a randomized clinical trial. J Am Coll Cardiol. 2013; 62:2318-2325. [PubMed: 23973694]

113. Narayan SM, Franz MR, Clopton P, Pruvot EJ, Krummen DE. Repolarization alternans reveals vulnerability to human atrial fibrillation. Circulation. 2011; 123:2922-2930. [PubMed: 21646498]

114. Narayan SM, Kazi D, Krummen DE, Rappel WJ. Repolarization and activation restitution near human pulmonary veins and atrial fibrillation initiation: a mechanism for the initiation of atrial fibrillation by premature beats. J Am Coll Cardiol. 2008; 52:1222-1230. [PubMed: 18926325]

115. Lalani GG, Schricker A, Gibson M, Rostamian A, Krummen DE, Narayan SM. Atrial conduction slows immediately before the onset of human atrial fibrillation: a bi-atrial contact mapping study of transitions to atrial fibrillation. J Am Coll Cardiol. 2012; 59:595-606. [PubMed: 22300695]

116. Engdahl J, Andersson L, Mirskaya M, Rosenqvist M. Stepwise screening of atrial fibrillation in a 75-year-old population: implications for stroke prevention. Circulation. 2013; 127:930-937. [PubMed: 23343564]

117. Healey JS, Connolly SJ, Gold MR, et al. Subclinical atrial fibrillation and the risk of stroke. N Engl J Med. 2012; 366:120-129. [PubMed: 22236222]

118. Deif B, Lowres N, Freedman SB. Screening for atrial fibrillation above age 65 detects an asymptomatic subset at high risk of stroke. Int J Cardiol. 2013; 164:371-372. [PubMed: 22964080]

119. Gillis AM, Rose MS. Temporal patterns of paroxysmal atrial fibrillation following DDDR pacemaker implantation. Am J Cardiol. 2000; 85:1445-1450. [PubMed: 10856390]

120. Uhlig K, Patel K, Ip S, Kitsios GD, Balk EM. Self-measured blood pressure monitoring in the management of hypertension: a systematic review and meta-analysis. Ann Intern Med. 2013; 159:185-194. [PubMed: 23922064]

121. Hanley J, Ure J, Pagliari C, Sheikh A, McKinstry B. Experiences of patients and professionals participating in the HITS home blood pressure telemonitoring trial: a qualitative study. BMJ Open. 2013; 3 
122. Rotheram-Borus MJ, Tomlinson M, Swendeman D, Lee A, Jones E. Standardized functions for smartphone applications: examples from maternal and child health. Int J Telemed Appl. 2012; 2012:973237. [PubMed: 23304136]

123. Knight BP, Gersh BJ, Carlson MD, et al. Role of permanent pacing to prevent atrial fibrillation: science advisory from the American Heart Association Council on Clinical Cardiology (Subcommittee on Electrocardiography and Arrhythmias) and the Quality of Care and Outcomes Research Interdisciplinary Working Group, in collaboration with the Heart Rhythm Society. Circulation. 2005; 111:240-243. [PubMed: 15657388]

124. Sweeney MO, Bank AJ, Nsah E, Koullick M, Zeng QC, Hettrick D, Sheldon T, Lamas GA. Search AV Extension and Managed Ventricular Pacing for Promoting Atrioventricular Conduction (SAVE PACe) Trial. Minimizing ventricular pacing to reduce atrial fibrillation in sinus-node disease. N Engl J Med. 2007; 357:1000-1008. [PubMed: 17804844]

125. Sanna T, Diener HC, Passman RS, et al. Cryptogenic stroke and underlying atrial fibrillation. N Engl J Med. 2014; 370:2478-2486. [PubMed: 24963567]

126. Chen PS, Chen LS, Fishbein MC, Lin SF, Nattel S. Role of the autonomic nervous system in atrial fibrillation: pathophysiology and therapy. Circ Res. 2014; 114:1500-1515. [PubMed: 24763467]

127. de Leeuw PW, Kroon AA. Clinical end points in baroreflex activation therapy: what do we need to know? Expert Rev Cardiovasc Ther. 2013; 11:683-688. [PubMed: 23750677]

128. Yu L, Scherlag BJ, Li S, Fan Y, Dyer J, Male S, Varma V, Sha Y, Stavrakis S, Po SS. Low-level transcutaneous electrical stimulation of the auricular branch of the vagus nerve: a noninvasive approach to treat the initial phase of atrial fibrillation. Heart Rhythm. 2013; 10:428-435. [PubMed: 23183191]

129. Lomuscio A, Belletti S, Battezzati PM, Lombardi F. Efficacy of acupuncture in preventing atrial fibrillation recurrences after electrical cardioversion. J Cardiovasc Electrophysiol. 2011; 22:241247. [PubMed: 20807278]

130. Gaita F, Corsinovi L, Anselmino M, Raimondo C, Pianelli M, Toso E, Bergamasco L, Boffano C, Valentini MC, Cesarani F, Scaglione M. Prevalence of silent cerebral ischemia in paroxysmal and persistent atrial fibrillation and correlation with cognitive function. J Am Coll Cardiol. 2013; 62:1990-1997. [PubMed: 23850917]

131. Oostema JA, Brown MD, DeLano M, Falzon L, Reeves MJ. Does diffusion-weighted imaging predict short-term risk of stroke in emergency department patients with transient ischemic attack? Ann Emerg Med. 2013; 61:62-71 e61. [PubMed: 22387087]

132. Aakre CA, McLeod CJ, Cha SS, Tsang TS, Lip GY, Gersh BJ. Comparison of clinical risk stratification for predicting stroke and thromboembolism in atrial fibrillation. Stroke. 2014; 45:426-431. [PubMed: 24309585]

133. Staals J, Makin SD, Doubal FN, Dennis MS, Wardlaw JM. Stroke subtype, vascular risk factors, and total MRI brain small-vessel disease burden. Neurology. 2014; 83:1228-1234. [PubMed: 25165388]

134. Wieczorek M, Hoeltgen R, Brueck M. Does the number of simultaneously activated electrodes during phased RF multielectrode ablation of atrial fibrillation influence the incidence of silent cerebral microembolism? Heart Rhythm. 2013; 10:953-959. [PubMed: 23567660]

135. Potpara TS, Lip GY, Apostolakis S. New anticoagulant treatments to protect against stroke in atrial fibrillation. Heart. 2012; 98:1341-1347. [PubMed: 22730480]

136. Azoulay L, Dell'aniello S, Simon TA, Renoux C, Suissa S. Initiation of warfarin in patients with atrial fibrillation: early effects on ischaemic strokes. Eur Heart J. 2013

137. Ogilvie IM, Newton N, Welner SA, Cowell W, Lip GY. Underuse of oral anticoagulants in atrial fibrillation: a systematic review. Am J Med. 2010; 123:638-645 e634. [PubMed: 20609686]

138. Apostolakis S, Sullivan RM, Olshansky B, Lip GY. Factors affecting quality of anticoagulation control among patients with atrial fibrillation on warfarin: the SAMe-TT(2)R(2) score. Chest. 2013; 144:1555-1563. [PubMed: 23669885]

139. Boriani G. Predicting the quality of anticoagulation during warfarin therapy: the basis for an individualized approach. Chest. 2013; 144:1437-1438. [PubMed: 24189852] 
140. Poli D, Antonucci E, Testa S, Lip GY. A prospective validation of the SAME-TTR score: how to identify atrial fibrillation patients who will have good anticoagulation control on warfarin. Intern Emerg Med. 2014; 9:443-447. [PubMed: 24652166]

141. Binici Z, Intzilakis T, Nielsen OW, Kober L, Sajadieh A. Excessive supraventricular ectopic activity and increased risk of atrial fibrillation and stroke. Circulation. 2010; 121:1904-1911. [PubMed: 20404258]

142. Cotter PE, Martin PJ, Ring L, Warburton EA, Belham M, Pugh PJ. Incidence of atrial fibrillation detected by implantable loop recorders in unexplained stroke. Neurology. 2013; 80:1546-1550. [PubMed: 23535493]

143. Moss JD. Left atrial appendage exclusion for prevention of stroke in atrial fibrillation: review of minimally invasive approaches. Curr Cardiol Rep. 2014; 16:448. [PubMed: 24408675]

144. Kramer JM, Smith PB, Califf RM. Impediments to clinical research in the United States. Clin Pharmacol Ther. 2012; 91:535-541. [PubMed: 22318614]

145. Emanuel EJ, Wood A, Fleischman A, Bowen A, Getz KA, Grady C, Levine C, Hammerschmidt DE, Faden R, Eckenwiler L, Muse CT, Sugarman J. Oversight of human participants research: identifying problems to evaluate reform proposals. Ann Intern Med. 2004; 141:282-291. [PubMed: 15313744]

146. Glotzer TV, Hellkamp AS, Zimmerman J, et al. Atrial high rate episodes detected by pacemaker diagnostics predict death and stroke: report of the Atrial Diagnostics Ancillary Study of the MOde Selection Trial (MOST). Circulation. 2003; 107:1614-1619. [PubMed: 12668495]

147. Services CfMaM. Meaningful Use. http://www.cms.gov/Regulations-and-Guidance/Legislation/ EHRIncentivePrograms/Meaningful_Use.html

148. Fleurence RL, Curtis LH, Califf RM, Platt R, Selby JV, Brown JS. Launching PCORnet, a national patient-centered clinical research network. J Am Med Inform Assoc. 2014; 4:578-582. [PubMed: 24821743]

149. Fineberg HV. The paradox of disease prevention: celebrated in principle, resisted in practice. JAMA. 2013; 310:85-90. [PubMed: 23821092]

150. Caldeira D, Martins C, Alves LB, Pereira H, Ferreira JJ, Costa J. Caffeine does not increase the risk of atrial fibrillation: a systematic review and meta-analysis of observational studies. Heart. 2013; 99:1383-1389. [PubMed: 24009307]

151. Lakkireddy D, Atkins D, Pillarisetti J, Ryschon K, Bommana S, Drisko J, Vanga S, Dawn B. Effect of yoga on arrhythmia burden, anxiety, depression, and quality of life in paroxysmal atrial fibrillation: the YOGA My Heart Study. J Am Coll Cardiol. 2013; 61:1177-1182. [PubMed: 23375926]

152. Adams MA, Sallis JF, Norman GJ, Hovell MF, Hekler EB, Perata E. An adaptive physical activity intervention for overweight adults: a randomized controlled trial. PLoS One. 2013; 8:e82901. [PubMed: 24349392]

153. Gillis AM, Verma A, Talajic M, Nattel S, Dorian P. CCS Atrial Fibrillation Guidelines Committee. Canadian Cardiovascular Society atrial fibrillation guidelines 2010: rate and rhythm management. Can J Cardiol. 2011; 27:47-59. [PubMed: 21329862]

154. Satterfield JM, Spring B, Brownson RC, Mullen EJ, Newhouse RP, Walker BB, Whitlock EP. Toward a transdisciplinary model of evidence-based practice. Milbank Q. 2009; 87:368-390. [PubMed: 19523122]

155. Lane DA, Langman CM, Lip GY, Nouwen A. Illness perceptions, affective response, and healthrelated quality of life in patients with atrial fibrillation. J Psychosom Res. 2009; 66:203-210. [PubMed: 19232232]

156. Borg Xuereb C, Shaw RL, Lane DA. Patients' and health professionals' views and experiences of atrial fibrillation and oral-anticoagulant therapy: a qualitative meta-synthesis. Patient Educ Couns. 2012; 88:330-337. [PubMed: 22738822]

157. Garcia-Alamino JM, Ward AM, Alonso-Coello P, Perera R, Bankhead C, Fitzmaurice D, Heneghan CJ. Self-monitoring and self-management of oral anticoagulation. Cochrane Database Syst Rev. 2010; 4:CD003839. [PubMed: 20393937]

158. Thrall G, Lane D, Carroll D, Lip GY. Quality of life in patients with atrial fibrillation: a systematic review. Am J Med. 2006; 119:448 e441-e419. [PubMed: 16651058] 
159. Nieuwlaat R, Capucci A, Camm AJ, et al. Atrial fibrillation management: a prospective survey in ESC member countries: the Euro Heart Survey on Atrial Fibrillation. Eur Heart J. 2005; 26:2422-2434. [PubMed: 16204266]

160. Spertus J, Dorian P, Bubien R, Lewis S, Godejohn D, Reynolds MR, Lakkireddy DR, Wimmer AP, Bhandari A, Burk C. Development and validation of the Atrial Fibrillation Effect on QualiTy-of-Life (AFEQT) Questionnaire in patients with atrial fibrillation. Circ Arrhythm Electrophysiol. 2011; 4:15-25. [PubMed: 21160035]

161. Eapen ZJ, Mi X, Qualls LG, Hammill BG, Fonarow GC, Turakhia MP, Heidenreich PA, Peterson ED, Curtis LH, Hernandez AF, Al-Khatib SM. Adherence and persistence in the use of warfarin after hospital discharge among patients with heart failure and atrial fibrillation. J Card Fail. 2014; 20:23-30. [PubMed: 24275703]

162. Hess CN, Rao SV, Kong DF, et al. Embedding a randomized clinical trial into an ongoing registry infrastructure: unique opportunities for efficiency in design of the Study of Access site For Enhancement of Percutaneous Coronary Intervention for Women (SAFE-PCI for Women). Am Heart J. 2013; 166:421-428. [PubMed: 24016489]

163. McNamara RL, Brass LM, Drozda JP Jr, et al. ACC/AHA key data elements and definitions for measuring the clinical management and outcomes of patients with atrial fibrillation: a report of the American College of Cardiology/American Heart Association Task Force on Clinical Data Standards (Writing Committee to Develop Data Standards on Atrial Fibrillation). Circulation. 2004; 109:3223-3243. [PubMed: 15226233]

164. Calkins H, Kuck KH, Cappato R, et al. 2012 HRS/EHRA/ECAS Expert Consensus Statement on Catheter and Surgical Ablation of Atrial Fibrillation: Recommendations for Patient Selection, Procedural Techniques, Patient Management and Follow-up, Definitions, Endpoints, and Research Trial Design: A report of the Heart Rhythm Society (HRS) Task Force on Catheter and Surgical Ablation of Atrial Fibrillation. Developed in partnership with the European Heart Rhythm Association (EHRA), a registered branch of the European Society of Cardiology (ESC) and the European Cardiac Arrhythmia Society (ECAS); and in collaboration with the American College of Cardiology (ACC), American Heart Association (AHA), the Asia Pacific Heart Rhythm Society (APHRS), and the Society of Thoracic Surgeons (STS). Endorsed by the governing bodies of the American College of Cardiology Foundation, the American Heart Association, the European Cardiac Arrhythmia Society, the European Heart Rhythm Association, the Society of Thoracic Surgeons, the Asia Pacific Heart Rhythm Society, and the Heart Rhythm Society. Heart Rhythm. 2012; 9:632-696. [PubMed: 22386883]

165. Califf RM, Platt R. Embedding cardiovascular research into practice. JAMA. 2013; 310:20372038. [PubMed: 24240926]

\section{Abbreviations}

$\begin{array}{ll}\text { ACEi } & \text { angiotensin-converting enzyme inhibitor } \\ \text { AF } & \text { atrial fibrillation } \\ \text { A-II } & \text { angiotensin-II } \\ \text { ANP } & \text { atrial natriuretic peptide } \\ \text { ARB } & \text { angiotensin receptor blocker } \\ \text { BP } & \text { blood pressure } \\ \text { BMI } & \text { body mass index } \\ \text { BNP } & \text { brain natriuretic peptide } \\ \text { CaMKII } & \text { calmodulin-dependent kinase II } \\ \text { DAD } & \text { delayed afterdepolari-zation }\end{array}$




\begin{tabular}{ll} 
EAD & early afterdepolarization \\
ECM & electrocardio-graphic mapping \\
EHR & electronic health record \\
ET-1 & endothelin-1 \\
GGA & geranyl-geranylacetone \\
GP & ganglionated plexi \\
HDAC6 & histone deacetylase-6 \\
HF & heart failure \\
HSP & heat shock protein \\
LA & left atrium \\
LAA & left atrial appendage \\
LGE-CMR & late gadolinium enhanced cardiac magnetic resonance imaging \\
LV & left ventricle \\
MRI & magnetic resonance imaging \\
NIH & National Institutes of Health \\
NOAC & non-vitamin K-dependent oral anticoagulant \\
NP & natriuretic peptide \\
OAC & oral anticoagulant \\
PAC & premature atrial contraction \\
PAF & paroxysmal atrial fibrillation \\
PV & pulmonary vein \\
PVI & pulmonary vein isolation \\
RAAS & renin-angiotensin-aldosterone system \\
RCT & randomized controlled trial \\
RSD & renal sympathetic denervation \\
SDB & trontered breathing \\
\hline
\end{tabular}




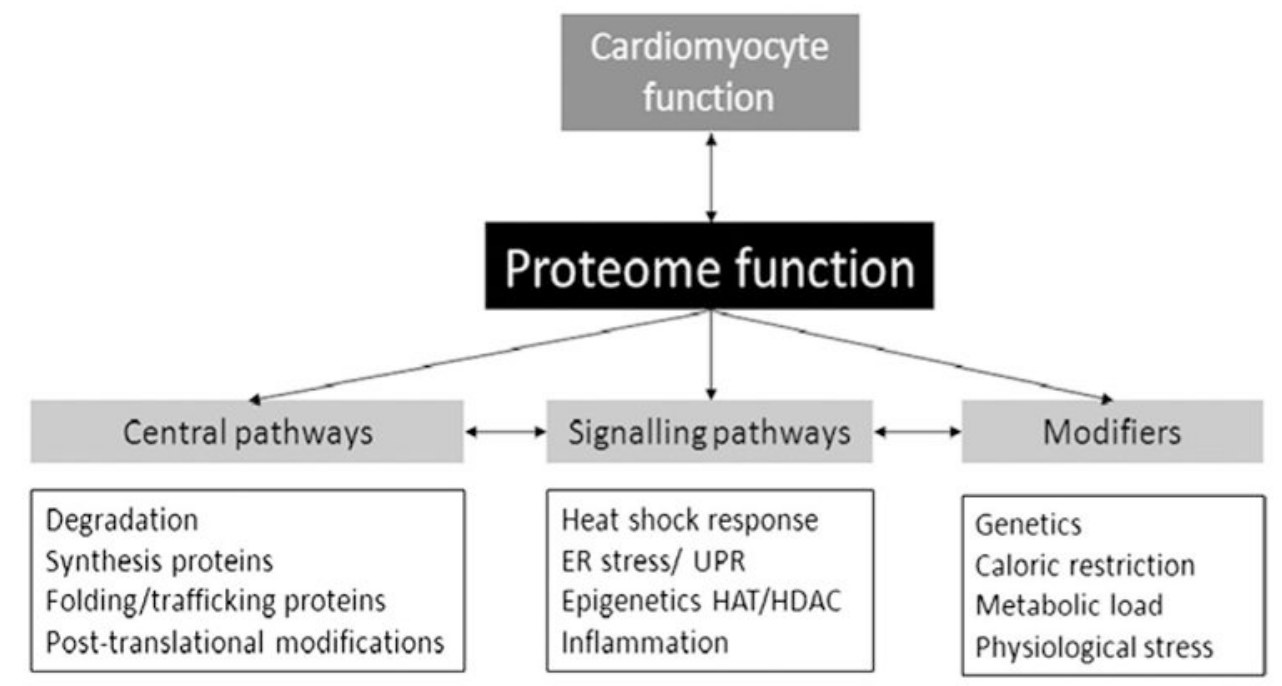

Figure 1.

Overview of the proteostasis network, related signaling pathways, and modifiers. The physiologic and functional state of cells, including atrial myocytes, is related to proteome function, which is managed by the proteostasis network. The proteostasis network includes central pathways involved in the degradation of "old" proteins, the synthesis of new proteins within the endoplasmic reticulum (ER), and the folding and trafficking of native proteins. Central pathways regulated by signaling pathways that are activated during stresses such as AF include the heat shock factor 1-induced heat shock response, ER stress, the unfolded protein responses (UPR), activation of histone deacetylase 6-(HDAC6), and systemic inflammation. Genetic variants, caloric restriction, metabolic load, and physiologic stresses can modify the proteostasis network. 


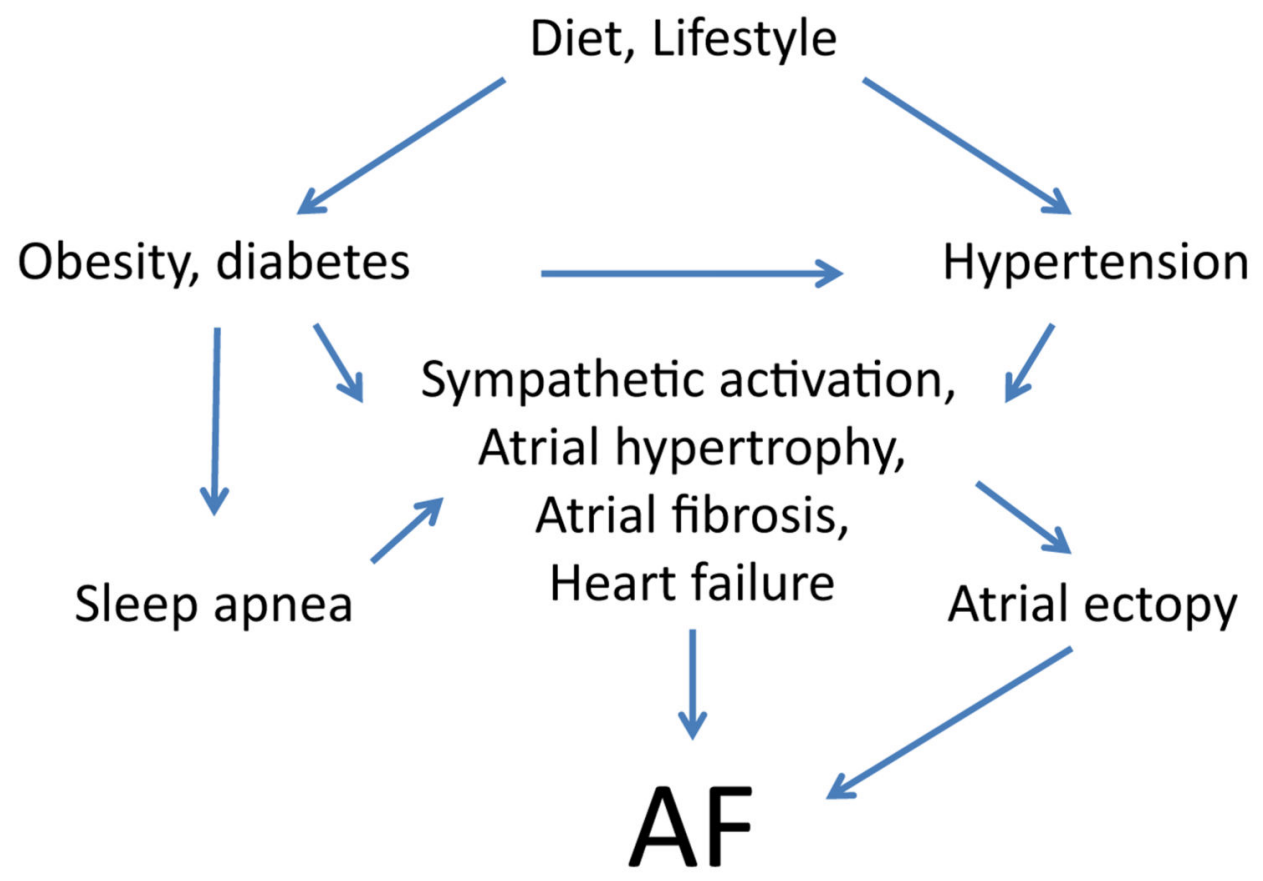

Figure 2.

Modifiable risk factors promote a substrate for AF. This figure illustrates the interactions of modifiable risk factors that lead to AF. Clinical and translational studies are needed to test the hypothesis that $\mathrm{AF}$ incidence and burden can be reduced by interventions that reduce the burden of patient-specific modifiable risk factors. Nonmodifiable risk factors (aging, genetics, etc) can further modulate the influence of the above risk factors on the development of AF. 


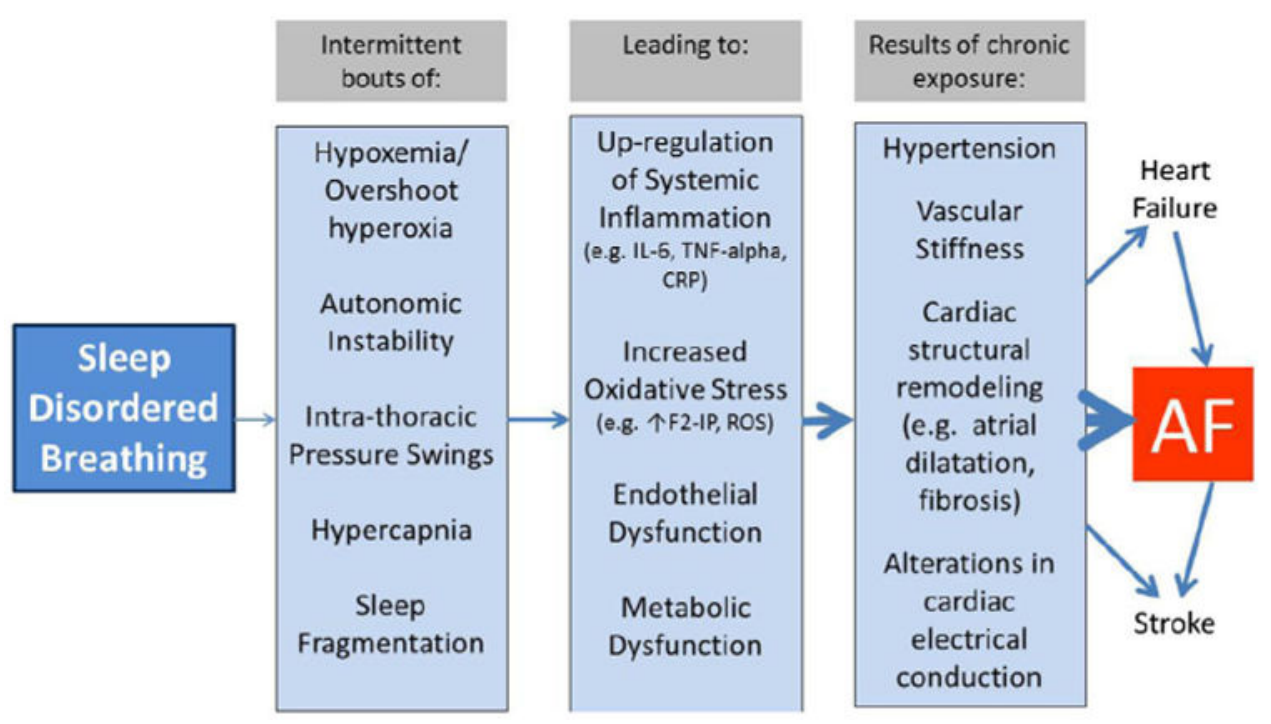

Figure 3.

Mechanisms linking sleep disordered breathing (SDB) with risk of AF. Continuous positive airway pressure (CPAP) can help to reduce the burden of SDB and thus may be a useful tool in the prevention of $\mathrm{AF}$, as well as the intermediate pathologic processes. 


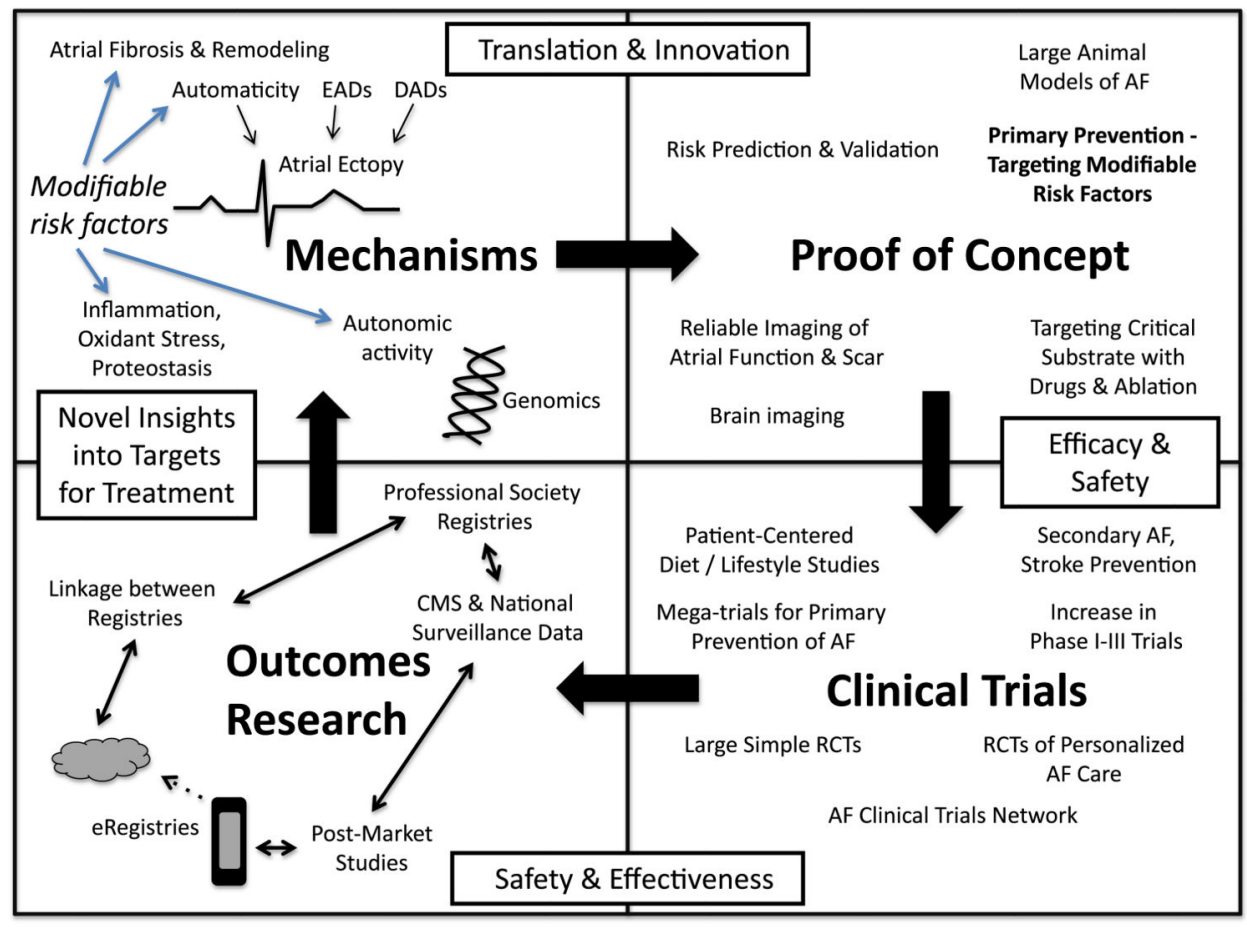

Figure 4.

Summary of the research targets and goals of the translational research cycle needed to systematically reduce the global incidence and burden of atrial fibrillation. 
Table 1

Pathways that might be targeted to advance AF prevention and treatment

\begin{tabular}{ll}
\hline Pathway & Candidate approaches \\
\hline Atrial ectopy & Calcium-dependent calmodulin kinase II (CaMKII) inhibitors \\
& Suppression of atrial myocyte oxidant production \\
& Selective late sodium channel blockers \\
& Modulation of ryanodine receptor oxidation/phosphorylation \\
& Inhibition of renin-angiotensin II-aldosterone, endothelin-1 and transforming growth factor- $\beta$ \\
signaling pathways & Modulation of fibroblast ion channels \\
Atrial fibrosis & Anti-inflammatory/antioxidant/antifibrotic drugs to attenuate fibroblast activation, proliferation and \\
& extracellular matrix accumulation \\
& miRNA targeting of profibrotic signaling pathways \\
Proteostasis/microtubule modulation & Modulation of heat shock protein/chaperone abundance \\
& Modulation of proteosome activity \\
& Suppression of atrial amyloid production/aggregation \\
& Modulation of microtubule stability/subcellular targeting \\
\hline
\end{tabular}

